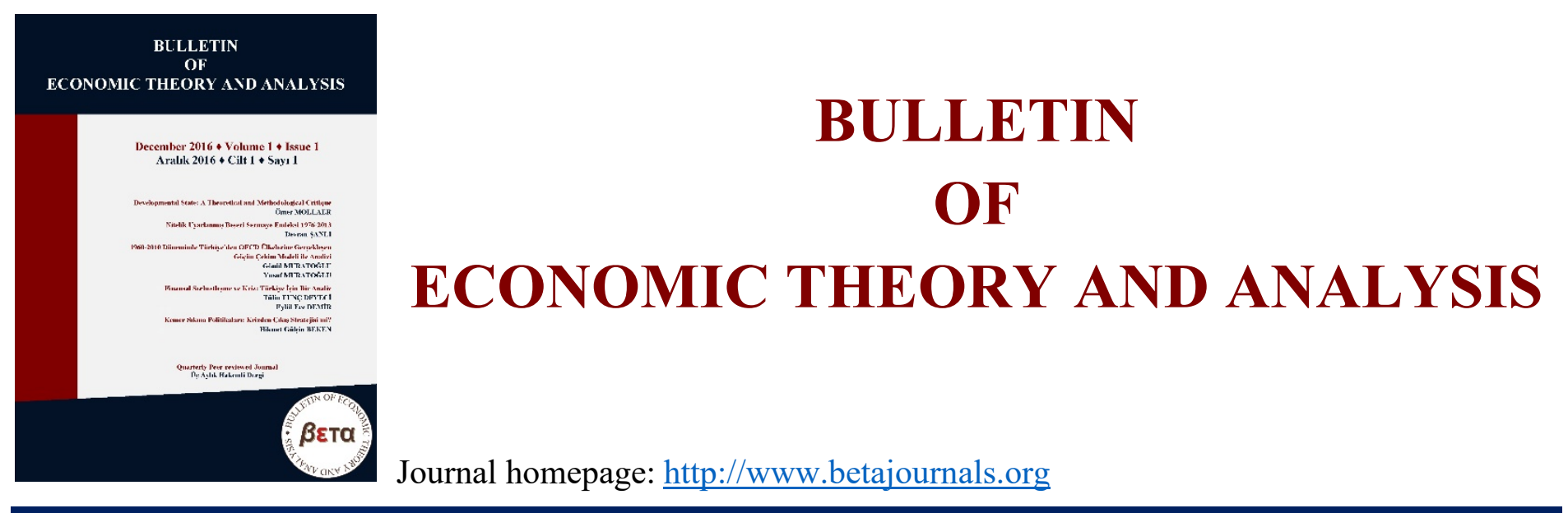

\title{
MINT Ülkelerinde Ara Girdi ve Nihai Talebin İthalat Bağımlılığı: Girdi-Çıktı Analizi
}

Şahin NAS $\odot$ https://orcid.org/0000-0003-3267-4432

To cite this article: Nas, Ş., (2021). MINT Ülkelerinde Ara Girdi ve Nihai Talebin İthalat Bağımlılı̆̆ı: Girdi-Çıktı Analizi. Bulletin of Economic Theory and Analysis, 6(1), 69-95.

Received: 04 Mar 2021

Accepted: 25 Jun 2021

Published online: 30 Jun 2021

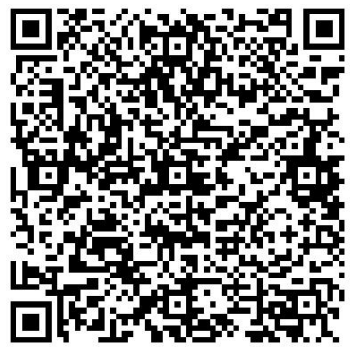




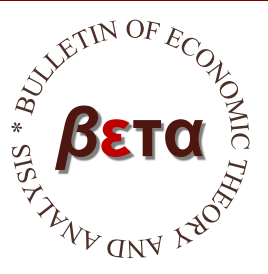

\title{
Bulletin of Economic Theory and Analysis
}

Volume VI, Issue 1, pp. 69-95, 2021

http://www.betajournals.org

Original Article / Araştırma Makalesi

Received / Alınma: 04.03.2021 Accepted/Kabul: 25.06.2021

\section{MINT Ülkelerinde Ara Girdi ve Nihai Talebin İthalat Bağımlılığı: Girdi-Çıktı Analizi}

\author{
Şahin NAS ${ }^{\mathrm{a}}$ \\ ${ }^{a}$ Arş. Gör. Dr., Şırnak Üniversitesi, İİBF, İktisat Bölümü, Şırnak, TÜRKİYE \\ (c) https://orcid.org/0000-0003-3267-4432
}

\section{ÖZ}

Dünyada dış ticaret serbestisi ile uluslararası ticarette hızlı gelişmeler meydana gelmiştir. Meydana gelen bu hızlı gelişmeler arasındaki en önemli gelişme, mal ve hizmet üretiminde yoğun bir şekilde ithal ara girdinin kullanılmasıdır. Özellikle gelişmekte olan ekonomiler başta olmak üzere küresel piyasaların karşılıklı bağımlılıkları artış göstermiştir. Gelişmekte olan ekonomiler kategorisinde yer alan MINT ülkeleri de uluslararası ticarete entegre olmuş önemli ekonomilerdir. $\mathrm{Bu}$ bağlamda çalışmanın temel amacı MINT ülkelerinin mal ve hizmet üretim faaliyetlerinde hem ara girdi hem de nihai talebin ithalat bağımlılı̆̆ını analiz etmektir. Ayrıca sektörel bağlamda yapılan toplam ihracatın ithalat bağımlılı̆̆ı da analiz edilmiştir. Çalışmada girdi-çıktı modelleri ile ithalat bağımlılığı analiz edilmiştir. Bu amaçla OECD veri tabanında yer alan ulusal girdi-çıktı tabloları kullanılmıştır. Elde edilen bulgulara göre MINT ülkelerinde imalat sanayii başta olmak üzere genel olarak sermaye yoğun sektörlerde ithalat bağımlılığının yüksek olduğu tespit edilmiştir. Emek yoğun ve düşük teknolojili sektörlerde ise ithalat bağımlılığının düşük olduğu tespit edilmiştir.

\author{
Anahtar Kelimeler \\ Girdi-Çıktı Analizi, \\ Uluslararası Ticaret, \\ İthalat Bağımlılı̆̆1 \\ JEL Kodu \\ F01, F10, F14, F19
}

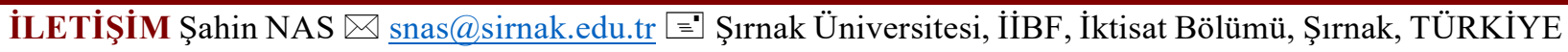




\section{The Import Dependency of Intermediate Input and Final Demand in the MINT Countries: Input-Output Analysis}

\begin{abstract}
In the world, with the liberalisation of foreign trade, there have been rapid developments occurred in international trade. One of the most important factors of these developments is the use of imported intermediate input in production. In this context, the interdependencies of global markets, especially for developing countries, have increased. MINT countries, which known as developing countries, are also important which are integrated into international trade. With this context, the main purpose of the study is analyses to import dependency of both intermediate input and final demand in the MINT countries. Also, the import dependency of total export is analysed for sectors. In this study, the import dependency is analysed with input-output models. In this purpose the national input-output table, which in the OECD database, are used. According to results, it is determined that import dependency is high in the capital-intensive sectors, especially in the manufacturing industry in the MINT countries. Also, it was determined that import dependency is low in the labourintensive and low-tech sectors.
\end{abstract}

Keywords

Input-Output

Analyses,

International Trade, Import Dependency

JEL Classification

F01, F10, F14, F19t

\section{Giriş}

Küresel ekonomide 1980 sonrası dönemde yaşanan değişim ve dönüşümler birçok gelişmekte olan ülkede kalkınma politikalarının ithal ikameci bir stratejiden ihracata dayalı veya dışa dönük bir stratejiye evrilmesine neden olmuştur (Veeramani, 2019). Ticari liberalizasyon, gümrük vergilerinin düşürülmesi, ulaştırma ve taşıma maliyetlerinin düşmesi, bilgi ve iletişim maliyetlerinin düşmesi ve teknolojiye dayalı üretimin hızlanması gibi faktörler küresel ekonomide yaşanan bu evriminin belli başlı nedenleri olduğu söylenebilir (Veeramani \& Dhir, 2017). Bu faktörler aynı zamanda dünya ekonomisinde üretimin parçalanmasına yol açmıştır (Banacloche, Cadarso \& Monsalve, 2020). Üretimin parçalanması, herhangi bir ülke için mal ve hizmet üretimini mekansızlaştırır ve uluslararası ticaretin hızla artmasına neden olur (Mattioli \& Lamonica, 2015: 5). Dünya ekonomisinde meydana gelen bu gelişmeler ile şekillenen günümüz uluslararası ticaret, ara girdi ticaretini artırmıştır. Bu bağlamda ara girdi ticareti uluslararası ticaretin önemli bir bileşeni haline gelmiştir ve özellikle gelişmekte olan ekonomilerde toplam ithalatın önemli bir kısmı ara girdi malları oluşturduğu söylenebilir (Lopez \& Yadav, 2010). Ülkeler bu şekilde nihai talepten ziyade daha çok mal ve hizmet üretim sürecinde uzmanlaşarak uluslararası ticarette katılmayı gerçekleştirirler (Veeramani \& Dhir, 2017). Üretimin uluslararası bölünme süreci, herhangi bir 
coğrafi bölgede gerçekleşen mal ve hizmet üretimindeki uzmanlık faaliyetleri ile daha da belirgin hale gelmiştir (Timmer, Miroudot \& Vries, 2019).

Dünya ekonomisinde 1980 sonrası yaşanan gelişmeler ve özellikle üretimin uluslararası bölünmesi sonucunda ülkelerin dünya piyasalarına entegrasyonu hızlandığı ileri sürülebilir. Herhangi bir ekonominin dünya piyasalarına entegrasyonu ise genel olarak ülkenin gayri safi yurtiçi hasıla (GSYİH) içindeki ihracat ve ithalat paylarının büyümesi ile hesaplanmaktadır. Bu anlamda bir ülkenin ihracat yoluyla küresel piyasalara iktisadi entegrasyonu dikey uzmanlaşma (vertical specialisation) yöntemi ile ampirik olarak analiz edilebilmektedir (Chen \& Chang, 2006: 321). Dikey uzmanlaşma, ülkelerin ihracat amaçlı mal ve hizmet üretim faaliyetlerinde ara girdi ithalatına bağlı olarak üretimin belirli aşamalarında uzmanlaşma sürecidir (Pahl \& Timmer, 2019: 459). Başka bir anlatımla dikey uzmanlaşma, üretimin uluslararası parçalanması ile mal ve hizmet üretim sürecinde ülkelerin karşılıklı bağımlılıklarının artmasına bağlı olarak üretim sürecinin belirli bir aşamasında her ülkenin uzmanlaşmasıdır (Hummels, Ishii \& Yi, 2001: 76). Bu bağlamda dikey uzmanlaşmanın olabilmesi için üç önemli koşulun gerçekleşmesi gerekmektedir. İlk olarak bir malın üretimi iki veya daha fazla art arda gelen süreçte gerçekleşmelidir. İkincisi, bir mal üretim sürecinde iki veya daha fazla ülke katma değer sağlamalıdır. Son olarak, üretim aşamasında en az bir ülke ithal ara girdi kullanmalıdır ve aynı zamanda üretilen çıktının bir kısmını ihraç etmelidir (Hummels, Ishii \& Yi, 2001; Mattioli \& Lamonica, 2015: 6).

1980 sonrası dünya ekonomisinde meydana gelen gelişmeler bağlamında düşünüldüğünde, MINT ülkeleri hem bölgesel hem de küresel bağlamda önemli uluslararası ticari ilişkilere sahip oldukları söylenebilir. Meksika, Endonezya, Nijerya ve Türkiye'nin baş harflerinden oluşan MINT kavramı hızlı ekonomik büyüme sağlamaları ve yükselen piyasaların önemini vurgulamak amacıyla 2013 yılında Goldman Sach iktisatçılarından Jim O’Neill tarafından kullanılmış ve popüler haline getirilmiştir (Lenee \& Oki, 2017; Scherer, Koning \& Tukker, 2019). MINT ülkeleri yükselen piyasalara sahip olmaları, yeni sanayileşen ülkeler olması, hızla büyüyen bir orta sınıfa sahip olmaları ve aynı zamanda hem bölgesel hem de küresel anlamda önemli etkilere sahip olması gibi bazı ortak özellikleri barındırmaktadırlar (Akpan, Isihak ve Asongu, 2014: 4). Bu ortak özelliklerin yanı sıra MINT ülkeleri genel olarak gelişmiş ülkelere göre daha dinamik bir genç nüfusa sahiptir ve nüfusları sürekli artış eğilimindedir (Casadella, 2018: 58-59). MINT ülkelerinin sahip oldukları coğrafi yapılarından dolayı önemli iktisadi avantajlar sağladıkları söylenebilir. Bu bağlamda Meksika, Latin Amerika bölgesinin büyüyen önemli ekonomilerinden biridir ve bölgede 
önemli bir iktisadi aktör olduğu söylenebilir. Ayrıca Meksika, Amerika Birleşik Devletleri (ABD) gibi büyük bir piyasa ile komşu durumundadır. Endonezya, Asya ülkeleri arasında en iyi ekonomik performansa sahip ekonomilerinden biridir ve dünya üretim merkezinin haline gelen Çin gibi önemli bir piyasaya yakındır. Türkiye, sahip olduğu jeopolitik konumu ile, hem Avrupa Birliği (AB) gibi büyük bir piyasaya komşudur hem de Ortadoğu ülkeleri ile önemli iktisadi ilişkilere sahip bir ülke konumundadır. Nijerya ise, Güney Afrika ekonomisinden sonra Afrika'nın en büyük ekonomisi olma özelliğine sahip ve aynı zamanda son dönemlerde Afrika ekonomisinin merkezi olma potansiyeline sahip olduğu söylenebilir. Ayrıca bu dört ülkeden sadece Nijerya G20 üyesi değildir. Bu ülkelerin diğer ortak bir özelliği de önemli derecede büyük bir iç pazara sahip olmalarıdır (Durotoye, 2014; Casadella, 2018).

$\mathrm{Bu}$ bağlamda çalışmanın temel amacı uluslararası ticaret kapsamında MINT ülkelerinde, mal ve hizmet üretiminde ara girdi ve nihai üretimin ithalat bağımlılığını analiz etmektedir. Çalışmada ilk olarak ithal ara girdi bağımlılı̆̆ı analiz edilmiş ve daha sonra nihai talebinin ithalat bağımlılığı analiz edilmiştir. Daha sonra MINT ülkelerinin küresel piyasalar ne derece katılım sağladığının göstergesi olan dikey uzmanlaşma oranı hesaplanmıştır. Çalışmada analiz yöntemi olarak girdi-çıktı modelleri kullanılmıştır. Girdi-çıktı modelleri, herhangi bir sektörün ekonomide nasıl bir katma değer sağladığını, sektörlerin karşılıklı bağımlılıklarını ve ayrıca sektörün veya ülkenin küresel piyasalara katılma oranını net bir şekilde hesaplama olanağı sağladığı için literatürde kullanılan uygun bir analiz yöntemidir (Haider, 2018). Aynı şekilde, girdi-çıktı modelleri herhangi bir ülkede yapılan ihracatın yerli ve yabancı katma değerinin ekonomiye katkısını analiz edebilmek ve ayrıca ülkenin dikey uzmanlaşma oranını daha doğru bir biçimde hesaplama olanağı sağladığı için diğer ampirik analizlere göre daha kapsamlı bir yaklaşımdır (Dağıstan, 2019). Bu anlamda girdi-çıktı modellerinin sağladığı avantajlardan dolayı bu çalışmanın literatüre önemli bir katkı sağlaması beklenmektedir. Çalışmada, analize dahil edilen ülkelerin hem ara girdi hem de nihai talebin ithalat bağımlılığı ve ayrıca dikey uzmanlaşma oranı analiz edildiğinden ve ayrıca literatürde yer alan diğer ampirik çalışmalardan farklılık göstermektedir. Ayrıca, OECD veri tabanında yer alan en güncel girdi-çıktı tabloları 2018 yılında derlenen, 20052015 dönemini kapsayan ve ISIC Rev. 4'e göre sınıflandırılmış olan tablolardır ve bu nedenle çalışmada 2018 yılında derlenen girdi-çıktı tablolarının kullanılması literatürde yer alan diğer çalışmalardan farklılık göstermektedir. Genel olarak, MINT ülkeleri için yapılan çalışmalarda, istihdam, büyüme, verimlilik gibi makro ekonomik düzeyde değişkenlerin ekonomiye etkisi 
ekonometrik gibi ampirik modeller ile analiz edilmektedir. $\mathrm{Bu}$ nedenle girdi-çıktı modellerinin uygulandığı bu çalışmanın literatüre önemli katkılar sağlayacağı düşünülmektedir. MINT ülkelerinin hem bölgesel hem de küresel anlamda dünya ekonomisinde önemli bir olgu haline gelmesi nedeniyle, bu ülkelerin uluslararası ticaretteki önemi ve rolünü analiz etmek çalışmanın temel motivasyonu olmuştur. Çalışmada OECD veri tabanında yer alan girdi-çıktı tablolarından yararlanılmıştır. OECD veri tabanında Nijerya'nın girdi-çıktı tablosu yer almadı̆̆ından Nijerya çalışmaya dahil edilmemiştir. Çalışma dört bölümden oluşmaktadır. Giriş bölümünden sonraki ikinci bölümde literatür taramasına yer verilmiştir. Üçüncü bölüm çalışmada kullanılan analiz yöntemine ve bulgulara yer verilmiştir. Dördüncü bölümde ise çalışmanın sonuç kısmı yer almaktadir.

\section{Literatür Taraması}

Dünya ekonomisinde 1980 sonrası dönemde, hızlı küreselleşme ve liberalizasyon politikaları ile birlikte uluslararası ticaret ülke ekonomileri için önemli bir faktör haline gelmiştir. Veeramani ve Dhir (2017)'in belirtikleri gibi, üretimin parçalanmasının hızla artması uluslararası ticaretinin yapısını değiştirmiştir. Dünya ekonomisinde üretimin parçalanması ile ülkelerin parçalanan üretim sürecine katılımı özellikle ara girdi ithalatı ile gerçekleşmiştir. $\mathrm{Bu}$ bağlamda ülkeler bir mal veya hizmetin nihai üretiminde bulunmaktan ziyade ara girdi ticareti ile uluslararası ticarete katılmayı hızlandırdılar ve bu nedenle ara girdi ticareti uluslararası ticaretin önemli bir bileşeni haline gelmiştir. Constantinescu, Mattoo \& Ruta (2019) ise bir ülke uluslararası ticarete katılım sürecinde ara girdi ithalatının verimliliği artırdığını öne sürmektedir. Ancak Lopez ve Yadav (2010) ve Ahmad, vd. (2018) bu durumun, yani sektörel anlamda ithal ara girdi durumuna bağlı olduğunu ve ithalat oranı artması durumunda özellikle ihracat değerinin ulusal ekonomiye katkısının azalacağını belirtmektedirler. Uluslararası ticarette meydana gelen bu gelişmeler girdi-çıktı modelleri ile analiz edilebilmektedir. Girdi-çıktı modelleri, bir ekonomide mal ve hizmet üretimi gerçekleştiren sektörlerin karşılıklı bağınlaşma yapısını analiz etmektedir (Aydoğuş, 2015). Aynı şekilde yukarıda da belirtildiği gibi, girdi-çıktı modelleri sektörlerin mal ve hizmet üretiminde ithal ara girdi kullanımı, nihai talebin ithalat bağımlılığını analiz etmek açısından daha uygun bir yöntemdir. Dolayısıyla uluslararası ticarette meydana gelen bu değişmeler ışığında bir ekonomide hem ara mal hem de nihai talep içerisindeki ithalatın rolünü görebilmek ve analiz edebilmek, küresel piyasaların evrim sürecini anlamak açısından önemli bir olgudur (Cardoso, Esteves \& Rua, 2013). Bu bağlamda hem ara mal hem de nihai talebin ithalat 
bağımlılığı ve ayrıca dikey uzmanlaşma ile ilgili literatürde yer alan bazı çalışmalar aşağıdaki gibi açıklanabilir.

Jangam ve Rath (2021), 2005-2015 dönemi 58 ülke için yaptıkları çalışmada, küresel değer zincirlerinin ekonomik büyümeyi hızlandırdığı ve aynı zamanda fonksiyonel uzmanlaşmanın (functional specialization) ekonomik büyüme için anahtar bir rol olduğuna yönelik bulgular elde edilmiştir. Çalışmada ayrıca özellikle yüksek teknoloji yoğun sektörlerde dikey uzmanlaşmanın ekonomik büyümeyi hızlandırdığg vurgulanmıştır.

Dağıstan (2019), Dünya Girdi-Çıktı Tabloları Veri Tabanında (WIOD) yer alan Türkiye’ye ait ulusal girdi-çıktı tabloları kullanarak 1995-2011 yılları için nihai ihracatın ithalat bağımlılığını hesaplamıştır. $\mathrm{Bu}$ çalışmada elde edilen bulgulara göre, çalışmanın kapsadığı dönem boyunca Türkiye ekonomisinde ihracatın ithalat bağımlılığı önemli derecede artış gösterdiği belirtilmiştir. Sektörel anlamda ihracatın ithalat bağımlılı̆̆ı en yüksek olan sektörler imalat sanayisi alt sektörleri olduğuna yönelik bulgular elde edilmiştir.

Mikulic ve Lovrincevic (2018) tarafından 2013 yılına ait girdi-çıktı tabloları kullanılarak Hırvatistan ekonomisi için yapılan çalışmada elde edilen bulgulara göre, kok kömürü, petrol, madencilik gibi ham madde gerektiren sektörler, motorlu taşıtlar, bilgisayar elektrik ve elektrik ürünleri imalatı gibi yüksek ve orta düzey teknolojik sektörlerde ithalat bağımlılığının yüksek olduğu ve bu sektörlerin uluslararası katma değer zincirlerine daha entegre olduğu vurgulanmıştır. Çalışmada genel anlamda tarım, madencilik ve imalat sanayi sektörlerinde ithalat bağımlılığının yüksek olduğu ve hizmet sektörlerinde ise ithalat bağımlılığının düşük olduğuna dair bulgular elde edilmiştir.

Prete, Giovannetti ve Marvasi (2018), 1995-2013 dönemi Kuzey Afrika ülkeleri için yaptıkları girdi-çıktı analizinde, Kuzey Afrika ülkelerinin uluslararası üretim ağına tam olarak entegre olmadığını ancak bunu zamanla artığını vurgulamaktadırlar. Çalışmada, Kuzey Afrika ülkelerinin küresel değer zincirlerine katılımın artması, hem ülkelere hem de bölgeye önemli iktisadi faydalar sağlayacağı belirtilmektedir.

Miroudot ve Ye (2018), WIOD veri tabanında yer alan girdi-çıktı tablolarını kullanarak yaptıkları çalışmada 2014 yılında ihracatın yurtiçi katma değerinin en yüksek olan iki ülke Brezilya $(\% 87,16)$ ve ABD $(\% 87,15)$, ihracatın yurtiçi katma değeri en düşük olan ülkeler ise sırasıyla Macaristan $(\% 48,13)$, Lüksemburg $(\% 33,96)$ ve Malta $(\% 34,51)$ olduğu belirtilmiştir. Çalışmada 
analize dahil edilen ülkelerde genel olarak, ihracatın yurtiçi katma değerinin daha yüksek olduğuna yönelik bulgular elde edilmiştir.

Gandoy (2017), 1995-2011 dönemleri için İspanya ekonomisinde küresel talep bileşenlerinin ithalat içeriklerine yönelik yaptığı çalışmada ithalat içeriğinin 2009 küresel kriz döneminde ciddi bir düşüş yaşamakla birlikte 1995-2011 dönemleri arasında genel anlamda önemli bir artış gösterdiği vurgulanmıştır. İspanya ekonomisinde ithalat bağımlılı̆̆ı özellikle yüksek teknolojili sektörlerde birçok Avrupa ülkesine göre daha yüksek olduğu vurgulanmıştır. Yine aynı şekilde çalışmada İspanya ekonomisinde yüksek ithalat bağımlılığının nedeni özellikle çok uluslu şirketlerin küresel değer zincirlerine katılımı ile gerçekleştiği ileri sürülmüştür.

Gündoğdu ve Saracoğlu (2016), WIOD veri tabanında yer alan ulusal girdi-çıktı tablolarını kullanarak 1995-2011 dönemleri için Türkiye ekonomisine yönelik yaptıkları çalışmada 1995 ve 2011 dönemleri arasında dikey uzmanlaşma oranının ortalama \%21 olduğu ve dönem boyunca artış eğiliminde olduğu vurgulanmıştır. Ancak 2007-2009 küresel finans krizine denk gelen dönemlerde dikey uzmanlaşma oranının ciddi anlamda düşüş gösterdiği gözlenmiştir. Bu çalışmada imalat sanayisinde 1995-2011 dönemleri arasında ihracatın ithalat içeriği orta-yüksek ve yüksek teknolojili alt sektörlerinde orta-alt teknolojili sektörlere göre daha hızlı arttığı vurgulanmıştır.

Lopes ve Santos (2015), WIOD’ta yer alan Portekiz'e ait ulusal girdi-çıktı tabloları kullanarak kauçuk ve plastik ürünleri imalatı için yaptıkları çalışmada bu sektörün 1995-2011 döneminde ihracatın ithalat bağımlılığının dönem başında \%31 iken dönem sonunda \%37'ye çıktığı belirtilmiştir. Ayrıca bu çalışmada Portekiz ekonomisinin 1995-2011 döneminde toplam ihracatın ithalat bağımlılı̆̆ı ortalama \%30 olarak hesaplanmıştır.

Mattioli ve Lamonica (2015), WIOD veri tabanını kullanarak 1995-2011 dönemini kapsayan 40 ülke için yaptıkları çalışmaya göre, ihracatın ithalat içeriği 40 ülkenin ortalamasının 1995 'te \%24 iken 2011 yılana gelindiğinde bu oran \%30'a çıkmıştır. Ancak bu yükselen trendin özellikle 2001, 2002 ve 2009 dönemlerinde ciddi anlamda düşüş gösterdiği ileri sürülmüştür. 2011 yılında ihracatın ithalat içeriği en yüksek olan Lüksemburg (\%62) en düşük ise Rusya ekonomisinde (\%6) gerçekleştiği bulgusu elde edilmiştir. Çalışmada dikey uzmanlaşma oranın en düşük olduğu ülkeler Rusya, ABD, Japonya, Brezilya ve İngiltere en yüksek olan ülkeler ise Malta, Lüksemburg, Tayvan, Belçika, Estonya ve İrlanda olduğu belirtilmiştir. 
Banga (2014), küresel değer zincirleri için yaptığı çalışmada küresel GSYİH içindeki dünya ihracat katma değeri payının 1995'te \%16, 2000'de \%17, 2005'te \%18, 2008'de \%21 ve 2009'da \%24 olarak hesaplamıştır. 2009 yılında ihracat katma değeri en yüksek olan ülkenin ABD olduğu belirtilmiştir. ABD’den sonra ihracat katma değeri en yüksek olan ülkeler sırasıyla Çin, Almanya, Japonya, İngiltere ve Fransa iken ihracat katma değerinin en düşük olduğu ülkeler ise Filipinler, Vietnam, Hong Kong ve Güney Afrika olarak hesaplanmıştır. Aynı çalışmada 2009 yılında ihracat katma değeri içindeki hizmetler sektörünün payının en yüksek olduğu ülke Hong Kong ve en düşük olan ise Endonezya olduğu belirtilmiştir.

Foster-McGregor ve Stehrer (2013), WIOD veri tabanından yararlanarak 1995-2011 dönemi kapsayan 41 ülke için yaptıkları çalışmada ihracatın ithalat içeriği dönem boyunca ortalama Meksika'da \%27-30, Endonezya'da \%10-15 ve Türkiye'de \%15-30 arasında değişkenlik gösterdiğine yönelik bulgular elde edilmiştir. Çin ekonomisinde bu oran \%16'dan \%22'ye, Hindistan ekonomisinde ise \%10'dan \%22'ye çıktığı hesaplanmıştır. Yine aynı şekilde büyük ülkelerde ihracatın ithalat içeriğinin düşük olduğu vurgulanmıştır. Ayrıca uluslararası üretim süreçlerine daha fazla entegre oldukça ihracatın ithalat içeriğinin zamanla artığı belirtilmiştir. $\mathrm{Bu}$ anlamda özellikle Doğu Avrupa ülkelerinin Avrupa'nın üretim ağında oynadıkları rollerinin önemli derecede artığı ileri sürülmüştür. NAFTA için ise bu oranlarının düşük olduğu belirtilmekte bu nedeni ise NAFTA antlaşmasının 1992 gibi daha erken bir tarihte imzalandığına bağlamaktadırlar.

Stehrer ve Stöllinger (2013), 1995-2011 dönemi Avusturya ekonomisi için yaptıkları çalışmada Avusturya ihracatının yabancı katma değerinin 1995'te \%25 civarı olduğu ve 2011 yılında ise \%35 civarında olduğu belirtilmiştir. Ancak yabancı katma değerinin 2008-2009 küresel finansal krizinden ciddi anlamda etkilendiği ileri sürülmüştür. Yine bu çalışmada 2011 y1lında yabanc1 katma değerinin en yüksek olduğu ülke Lüksemburg ve en düşük olduğu ülke ise Rusya olduğu belirlenmiştir. Sektörel anlamda yabancı katma değeri en yüksek olan sektör kok kömürü, rafine edilmiş petrol ve nükleer enerji (\%79) ve bu sektör dışında genel olarak yabancı katma değeri yüksek olan sektörler yüksek ve orta teknolojili sektörler olduğu ileri sürülmektedir. Yabancı katma değeri yüksek olan diğer sektörler ise ulaştırma ekipmanları sektörü (\%50), temel metal sanayi (\%47), makine sanayisi (\%37), ve elektirik ve optik teçhizat sektörü (\%37) olarak hesaplanmıştır. 
Cruz vd. (2013) Meksika ekonomisinde imalat sanayisinde yapılan ihracatın yurtiçi katma değer oranın yaklaşık \%34 olduğuna dair bulgular elde etmişlerdir. Bu çalışmada Meksika ekonomisinde yurtiçi katma değerinin \%50'den az olan sektörlerinin ülkenin imalat sanayi ihracatının yaklaşık \%80'inini oluşturduğu ileri sürülmüştür. Yurtiçi katma değerinin düşük olduğu sektörler bilgisayar aygıtları, ses ve video aygıtları, iletişim aygıtları, yarı-iletken ve elektronik ve elektrikli ekipmanlar olarak belirlenmiştir. Benzer şekilde çalışmada yurtiçi katma değeri \%65'in üzerinde olan sektörlerin ise Meksika'nın toplam imalat sanayi ihracatının yaklaşık \%5'ini oluşturduğu belirtilmiştir.

Powers (2012), yaptığı çalışmada 2004 yılında ihracatın yurtiçi katma değerinin GSYİH içindeki payının dünya çapında \%15 olduğunu ileri sürmektedir. Aynı şekilde ihracatın yurtiçi katma değerinin GSYİH içindeki payı gelişmiş ülkelerde \%11, yeni sanayileşen Asya ülkelerinde \%34,7, yükselen Asya ülkelerinde \%23,9 ve diğer yükselen ekonomilerde ise \%24 olduğunu vurgulamaktadır. Aynı çalışmada dünya çapında yapılan ihracatın yabancı katma değerinin \%21,6 olduğu belirtilmektedir. Ülke grupları bazında ise, bu oran gelişmiş ülkelerde \%14,2, yeni sanayileşen Asya ülkelerinde \%35,1, yükselen Asya ülkelerinde \%34,1 ve diğer yükselen ekonomilerde ise \%20,4 olduğunu belirtmektedir.

Pei vd. (2011), 1997-2005 dönemi Çin girdi-çıktı tabloları kullanarak yaptıkları analizde Çin ekonomisinde yurtiçi nihai talebin önemli bir dinamik olduğu vurgulanmıştır. Aynı çalışmada dikey uzmanlaşma oranı için yapılan analizde, ihracatın ithalat bağımlılı̆̆ 1997 'de \%21 ve 2005 'te ise \%30 olarak hesaplanmıştır. Dönem sonunda ise ihracatın ithalat bağımlılığının \%8 arttığı belirtilmiştir.

Pula ve Peltonen (2011), Asya uluslararası girdi-çıktı tablolarını kullanarak yaptıkları çalışmada, Asya ülkelerinde yurtiçi nihai talebin katma değere etkisi 1995 yılında \%72 iken bu oran 2006 yılında \%64 olarak hesaplanmıştır. Bu çalışmada, Asya ülkelerinin Avrupa Birliği (AB) ülkelerine yapılan ihracattan elde edilen katma değer \%2,1, Japonya'ya yapılan ihracattan elde edilen katma değer \%3,9 ve Amerika Birleşik Devletleri'ne (ABD) yapılan ihracattan elde edilen katma değer \%5,3 olarak hesaplanmıştır. Yine benzer şekilde Çin'in AB'ye yaptığı ihracattan elde ettiği katma değer \%2,1, Japonya'ya yapılan ihracattan elde edilen katma değer \%4,1 ve ABD’ye yapılan ihracattan elde edilen katma değer \%4,5 olduğu belirtilmiştir. 
He ve Zhang (2010), Çin ekonomisinin dönüşümünde diş ticaret ve yurtiçi talebini etkisini analiz etmek için yaptıkları çalışmada toplam talep içerisindeki ihracatın payı 1997'de \%8,3 2000'de \%9 ve 2002'de \%9,9 olduğu belirtilmiştir. Aynı şekilde çalışmada 2002'de toplam ihracatın \%35'inin tekstil, dikiş, deri ve kürk ürünleri ve \%15'inin de diğer imalat sanayi ürünleri olduğu belirtilmiştir. İmalat sanayisinden sonra ihracat içindeki en yüksek pay makine ve teçhizat sektörü olduğu belirtilmiş ve bu sektörün toplam ihracat içindeki payı 2002'de \%23,5 olarak hesaplanmıştır.

Wang ve Powers (2009) yaptıkları çalışmada, Doğu Asya imalat sanayisinde yapılan ihracat katma değeri en yüksek olan sektör elektronik ürünler olduğu belirtilmiştir. Doğu Asya'da bu sektörde yapılan ihracattan elde edilen katma değer 1990'da \%31,8 ve 2000'de \%37,5 olarak hesaplanmıştır. Bu sektörden sonra bölgede imalat sanayisinde ihracat katma değeri yüksek olan diğer bir sektör motorlu araçlar sektörüdür ve sektörde ihracat katma değeri 1990'da \%22,4, 2000 'de ise \%17,2 olarak hesaplanmıştır.

\section{Analiz Yöntemi ve Bulgular}

MINT ülkeleri için 2005-2015 döneminde ithalat bağımlılığını hesaplamak amacıyla girdiçıktı tablolarından yararlanılmıştır. Girdi-çıktı tabloları bir ekonomide mal ve hizmet üretimi yapan sektörler arasındaki yapısal ilişkileri göstermektedir (Mikulic \& Lovrincevic, 2018). Bu bağlamda girdi-çıktı tabloları, üretim faaliyeti gerçekleştiren sektörlere ait hesapların tablo haline getirilmesiyle elde edilir. Mal ve hizmet üretimi gerçekleştiren her bir sektör girdi-çıktı tablolarında bir satır ve bir sütün olmak üzere iki şekilde yer alır. Girdi-çıktı tablosunun satırı herhangi bir sektör tarafından üretilen mal ve hizmet çıktısının nasıl kullanıldığını ya da başka bir deyişle üretilen mal ve hizmetlere yönelik farklı talep bileşenlerini göstermektedir. Ayrıca satırlarda her bir sektör tarafında üretilen mal ve hizmet çıktısının kullanım alanları yer alır. Bu anlamda bir sektör tarafında elde edilen çıktı ara mal ve nihai mal olarak kullanılır. Tablonun sütunları ise, herhangi bir sektörün mal ve hizmet çıktısı üretebilmek için kullandığı girdileri göstermektedir (Aydoğuş, 2015). Girdi-çıktı tabloları temelde üç ana bölmeden oluşmaktadır. Birinci bölme, ara

mal işlemleri olarak bilinen sektörler arası karşılıklı yapısal bağınlaşmayı göstermektedir. İkinci bölme her bir sektör tarafında üretilen mal ve hizmetlere olan nihai talebi göstermektedir. Üçüncü bölmede ise, temel girdiler yer almaktadır (Rohman, 2013). Girdi-çıktı tablolarından yararlanılarak Wassily Leontief tarafından geliştirilen girdi-çıktı analizi, iktisadi yapıda faaliyet gösteren 
sektörler arasındaki karşılıklı bağınlaşmayı ve herhangi bir sektör tarafından üretilen belirli bir çıktı miktarı için doğrudan ve dolaylı ara girdi gereksinimi matris cebrini kullanarak tahmin eden matematiksel bir yöntemdir (Mikulic \& Lovrincevic, 2018; Aydoğuş, 2015).

Girdi-çıktı tablolarından yararlanılarak herhangi bir ekonomide nihai talep ve gayri safi üretim arasındaki ilişki matris cebri ile hesaplanabilir. Bu bağlamda toplam $\boldsymbol{n}$ sektörden ${ }^{1}$ oluşan bir ekonomide $\boldsymbol{i}$ sektörünün toplam üretimi $\boldsymbol{x}_{\boldsymbol{i}}$ toplam nihai talebi $\boldsymbol{f}_{\boldsymbol{i}}$ ve $\boldsymbol{z}_{\boldsymbol{i}}$ sektörler arası ara mal akışını göstermesi durumunda ekonomide nihai talep ve gayri safi üretim arasındaki denklik aşağıdaki gibi olur (Miller \& Blair, 2009):

$$
\mathrm{x}_{\mathrm{i}}=\mathrm{z}_{\mathrm{i} 1}+\ldots+\mathrm{z}_{\mathrm{ij}}+\ldots+\mathrm{z}_{\mathrm{in}}+\mathrm{f}_{\mathrm{i}}=\sum_{i=1}^{n} z_{i j}+\mathrm{f}_{\mathrm{ij}}
$$

Denklem (1) $\boldsymbol{n}$ tane sektör için düzenlenirse denklem (2) elde edilir:

$$
\begin{gathered}
\mathrm{x}_{1}=\mathrm{z}_{11}+\ldots \mathrm{z}_{\mathrm{ij}}+\ldots+\mathrm{z}_{1 \mathrm{n}}+\mathrm{f}_{1} \\
\vdots \\
\mathrm{x}_{\mathrm{i}}=\mathrm{z}_{\mathrm{i} 1}+\ldots \mathrm{z}_{\mathrm{ij}}+\ldots+\mathrm{z}_{\mathrm{in}}+\mathrm{f}_{\mathrm{i}} \\
\vdots \\
\mathrm{X}_{\mathrm{n}}=\mathrm{z}_{\mathrm{n} 1}+\ldots \mathrm{z}_{\mathrm{nj}}+\ldots+\mathrm{z}_{\mathrm{nn}}+\mathrm{f}_{\mathrm{i}} \\
\text { Burada; } \mathbf{X}=\left[\begin{array}{c}
x_{1} \\
\vdots \\
x_{n}
\end{array}\right], \mathbf{Z}=\left[\begin{array}{ccc}
Z_{11} & \cdots & z_{1 n} \\
\vdots & \ddots & \vdots \\
z_{n 1} & \cdots & z_{n n}
\end{array}\right] \text { ve } \mathbf{F}=\left[\begin{array}{c}
f_{1} \\
\vdots \\
f_{n}
\end{array}\right], \mathrm{x} \text { ve f birer vektör ve } \mathrm{Z} \text { ise } \boldsymbol{n} \boldsymbol{x} \boldsymbol{n} \text { şeklinde }
\end{gathered}
$$

bir matrisi göstermektedir. Dolayısıyla nihai talep ile çıktı arasındaki denklem matris notasunuyla gösterilirse aşağıdaki denklem (3) elde edilir:

$$
\mathrm{X}=\mathrm{Z} \mu+\mathrm{F}^{2}
$$

Denklem (3)'te; $\mathbf{A}_{\mathbf{d}}=\mathbf{Z} . \widehat{\boldsymbol{X}}^{-\mathbf{1}} ; \mathbf{A}_{\mathbf{d}}=\sum \boldsymbol{a}_{\boldsymbol{i} \boldsymbol{j}}$ ve buradaki Ad teknik katsayılar matrisini ifade etmektedir ve $\boldsymbol{n} \boldsymbol{x n}$ matrisi şeklindedir $(\mathrm{Raa}, 2005)^{3}$. Bu durumda denklem (3) tekrar düzenlenirse;

$$
X=A X+F(C+G+I+\operatorname{Exp})
$$

Denklem (4) X için çözülürse aşağıdaki denklem (5) elde edilir:

\footnotetext{
${ }^{1}$ Çalışmada OECD Ulusal Girdi-Çıktı tabloları kullanılmıştır. OECD ulusal girdi-çıktı tabloları 36 alt sektörden oluşmaktadır bu nedenle çalışmada $\boldsymbol{n = 3 6}$ olarak alınmıştır. Bknz; OECD, Input-Output Tables (https://stats.oecd.org).

${ }^{2}$ Denklemde yer alan $\boldsymbol{\mu}$ sembolü toplam vektörünü ifade etmektedir. Bknz. Miller ve Blair, 2009.

${ }^{3} \mathbf{X}$ ifadesinin üzerindeki şapka $\mathrm{X}$ ifadesinin diagonal bir matris olduğunu ifade etmektedir.
} 


$$
X=\left(I-A_{d}\right)^{-1} \cdot F(C+G+I+\operatorname{Exp})^{4}
$$

Bu denklem (5) ile her bir ekonomide denge üretim miktarı elde edilmiş olur (Mikulic \& Lovrincevic, 2018; Miller \& Blair, 2009; Aydoğuş, 2015).

Buradan hareketle belirli bir ekonomide sektörlerin ara mal ve nihai mal üretiminde ithalat bağımlılığı hesaplanabilir. Bu hesaplama teknik katsayılar matrisi (A) hesaplanarak yapılabilir. Girdi-çıktı tablolarında teknik katsayılar matrisi yurtiçi teknik katsayılar matrisi $\left(\mathbf{A}^{\mathbf{d}}\right)$ ve ithal katsayılar matrisi $\left(\mathbf{A}^{\mathbf{m}}\right)$ olmak üzere iki kısımdan oluşmaktadır. Bu çerçevede teknik katsayılar matrisi aşağıdaki gibi elde edilir (Leontief, 1986: 23-26; Johnson \& Noguera, 2012):

$$
\left[\begin{array}{ccc}
a_{11} & \cdots & a_{1 n} \\
\vdots & \ddots & \vdots \\
a_{n 1} & \cdots & a_{n n}
\end{array}\right]=\left[\begin{array}{ccc}
a_{11}^{d} & \cdots & a_{1 n}^{d} \\
\vdots & \ddots & \vdots \\
a_{n 1}^{d} & \cdots & a_{n n}^{d}
\end{array}\right]+\left[\begin{array}{ccc}
a_{11}^{m} & \cdots & a_{1 n}^{m} \\
\vdots & \ddots & \vdots \\
a_{n 1}^{m} & \cdots & a_{n n}^{m}
\end{array}\right]
$$

Denklem (6)’yı matris notasyonu ile düzenlenirse aşağıdaki denklem (7) elde edilir:

$$
A=A^{d}+A^{m}
$$

Denklem (7)'de yer alan ithal katsayılar matrisi $\mathbf{A}^{\mathbf{m}}=\mathbf{Z}^{\mathbf{m}} \cdot \widehat{\boldsymbol{X}}^{\mathbf{1}} ; \mathbf{A}^{\mathbf{m}}=\sum \boldsymbol{a}^{\mathbf{m}}{ }_{\boldsymbol{i} \boldsymbol{j}}$ şeklinde elde edilir. Elde edilen ithalat katsayılar matrisinin $\left(\mathbf{A}^{\mathbf{m}}=\sum \boldsymbol{a}^{\boldsymbol{m}}{ }_{\boldsymbol{i} \boldsymbol{j}}\right)$ sütunlarının toplamı $\boldsymbol{j}$ sektörünün nihai talebinde meydana gelen bir değişme durumunda doğrudan geri bağlantı etkilerini ifade etmektedir. İthalat katsayılar matrisinin $\left(\mathbf{A}^{\mathbf{m}}=\sum \boldsymbol{a}^{\boldsymbol{m}}{ }_{\boldsymbol{i} \boldsymbol{j}}\right)$ satırlarının toplamı ise, i sektörünün ileri bağlantı etkilerini ifade etmektedir (Thirlwall, 1986: 238-242; Mikulic ve Lovrincevic, 2018: 2009). Dolayısıyla bu şekilde hesaplanan ithal girdi katsayılar matrisi bir ekonomide doğrudan ithal ara girdi etkilerini vermektedir. Bununla birlikte bir ekonomide hem dolaylı hem de doğrudan ithal etkiler yani toplam ithal ara girdi etkileri hesaplanabilir. Bu bağlamda toplam ithal ara girdi etkileri ithalat ters matrisi (R) yardımıyla hesaplanabilmektedir. İthalat ters matrisinin (R) hesaplanmasında Leontief ters matrisinden $(\mathbf{I}-\mathbf{A})^{-\mathbf{1}}$ yararlanılmaktadır. Dolayısıyla ithal ters matrisi aşağıdaki gibi elde edilir (Reis \& Rua, 2009; Amar, Landau \& Wirkierman, 2016; Bravo \& Alvarez, 2012):

$\mathrm{R}=\mathrm{A}^{\mathrm{m}} \mathrm{x}(\mathrm{I}-\mathrm{A})^{-1}$

İthalat ters matrisi yani R'deki her sütünün toplamı belirli bir $\boldsymbol{j}$ sektöründe yerli veya

${ }^{4}$ I $\boldsymbol{n} \boldsymbol{x} \boldsymbol{n}$ şeklinde birim matrisi ifade etmektedir. Ayrıca denklemdeki (I-Ad) ${ }^{-1}$ ifadesi Leontief Ters Matrisini (L) göstermektedir 
yabancı nihai talepteki bir değişmenin neden olduğu ithalat gereksinim oranını (import requirements ratio (IRR)) vermektedir. Başka bir deyişle matris sütunlarının toplamı $\boldsymbol{j}$ sektörünün bir birimlik çıktı üretimi karşısında ne kadar ithalat yapması gerektiğini ifade etmektedir. İthalat gereksinim oranı aşağıdaki gibi elde edilmektedir (Duman \& Özgüzer, 2013):

$$
\mathrm{R}_{\mathrm{j}}=\sum_{j=1}^{n} r_{i j}(\mathrm{j}=1,2, \ldots, \mathrm{n})
$$

$\mathbf{R}_{\mathbf{j}}$ katsayısı yükselmesi (düşmesi) üretim faaliyeti gerçekleştiren $\boldsymbol{j}$ sektörünün ithalat gereksinim oranın artığı (azaldığı) ya da başka bir ifade ile sektör üretimin ithalat bağımlılı̆̆ının artığ1 (azaldığı) anlamına gelmektedir (Bravo \& Alvarez, 2012; Cordoso, Esteves \& Rua, 2013).

İthalat katsayılar matrisi elde edildikten sonra bir ekonomide herhangi bir $\boldsymbol{j}$ sektörü tarafından üretilen mal ve hizmetlere olan nihai talebin ne kadar ithalat içerdiği hesaplanabilir. Nihai talebin ithalat içeriğinin hesaplanmasında ithalat ters matrisinden $(\mathbf{R})$ yararlanılır. $\mathrm{Bu}$ bağlamda bir ekonomide nihai talebin ithalat içeriği aşağıdaki gibi hesaplanır (Timmer, 2015; Mikulic \& Lovrincevic, 2018):

$$
A^{m} \times(I-A)^{-1} \times F^{d} ; F^{d}=C^{d}+G^{d}+I^{d}
$$

Denklem (9) bir ekonomide yurt içi nihai talebin $\left(\mathbf{F}^{\mathbf{d}}\right)$ ithalat içeriğini göstermektedir. Burada yurtiçi nihai talep, hane halkı harcamaları, hükümet harcamaları ve yatırım harcamaları olmak üzere üç bileşenden oluşmaktadır. Benzer bir şekilde yurtdışı nihai talebin ithalat içeriğini hesaplamak için aşağıdaki denklemden yararlanılır (Johnson \& Noguera; 2012):

$$
\mathrm{A}^{\mathrm{m}} \times(\mathrm{I}-\mathrm{A})^{-1} \times \mathrm{F}^{\mathrm{f}} ; \mathrm{F}^{\mathrm{f}}=\text { Exp. }
$$

Denklem (10)'de yer alan yurtdışı nihai talep, ulusal bir ekonomide yapılan toplam nihai ihracattan (Exp.) oluşmaktadır. Denklem (10)'dan hareketle bir ekonomide dikey uzmanlaşma (vertical specialisation) oranı hesaplanabilir. Dikey uzmanlaşma, uluslararası mal ve hizmet ticaretinde üretimin parçalanma derecesini ifade etmektedir. Üretimin parçalanması (fragmentation) bağlamında, herhangi bir ülke ihracat yapmak amaciyla mal ve hizmet üretiminde kullanılmak üzere ara girdi ithalatına dayanarak uluslararası üretimin belirli aşamalarında uzmanlaşabilir. Bu şekilde meydana gelen uluslararası parçalı üretim süreci dikey uzmanlaşma olarak tanımlanmaktadır (Timmer, Miroudot \& Vries, 2019; Pahl \& Timmer, 2019). Bu bağlamda bir ülkenin uluslararası ticarette dikey uzmanlaşma oranı aşağıdaki gibi hesaplanmaktadır (Hummels, Ishii \& Yi, 2001): 
Dikey uzmanlaşma (VS) oran $1=\mu \cdot \mathrm{A}^{\mathrm{m}} \cdot\left(\mathrm{I}-\mathrm{A}^{\mathrm{d}}\right)^{-1} \cdot \operatorname{Exp} / \operatorname{Exp}^{\mathrm{t}}$

Denklem 11'de yer alan $\boldsymbol{\mu} 1 \mathrm{x} \mathrm{n}$ şeklinde bir toplam vektörünü, $\boldsymbol{A}^{m} \mathrm{n} \times \mathrm{n}$ şeklinde ithalat katsayılar matrisini, $\left(\boldsymbol{I}-\boldsymbol{A}^{d}\right)^{-1}$ n x n şeklinde Leontief ters matrisini, $\operatorname{Exp} \mathrm{n} \times 1$ şeklinde ihracat vektörünü ve $\boldsymbol{E x p}^{t}$ ise ülkenin belirli bir yılda toplam ihracatını ifade etmektedir.

\subsection{Bulgular}

OECD veri tabanında yer alan MINT ülkelerine ait girdi-çıktı tabloları kullanılarak yapılan analiz sonucunda, MINT ülkelerinde ara mal ve nihai talebinin ithalat içeriklerine yönelik elde edilen bulgular aşağıdaki tablolarda yer verilmiştir. MINT ülkeler grubunda yer alan Nijerya'nın girdi-çıktı tabloları OECD veri tabanında olmadığından Nijerya analize dahil edilmemiştir. $\mathrm{Bu}$ nedenle aşağıdaki tablolarda sadece Meksika, Endonezya ve Türkiye ekonomilerine yönelik elde edilen bulgular yer almaktadır. Bu doğrultuda MINT ülkelerinde sırasıyla ithal ara mal bağımlılı̆̆ı, nihai talebin ithal bağımlılı̆̆ hesaplanmış ve bu ülkelerin sektörel olarak dikey uzmanlaşma oranları hesaplanmıştır. İthalat bağımlılığı en yüksek olan ilk 15 sektör tablolarda gösterilmiştir. 
Tablo 1

MINT Ülkelerinde İthal Ara Girdi Bă̆ımlılı̆̆ ${ }^{5}$

\begin{tabular}{|c|c|c|c|c|c|c|c|c|c|c|c|c|c|}
\hline \multirow{2}{*}{ Ülke } & \multirow{2}{*}{ Sira } & \multicolumn{2}{|c|}{2005} & \multicolumn{2}{|c|}{2008} & \multicolumn{2}{|c|}{2009} & \multicolumn{2}{|c|}{2010} & \multicolumn{2}{|c|}{2014} & \multicolumn{2}{|c|}{2015} \\
\hline & & Sektör & IRR & Sektör & IRR & Sektör & IRR & Sektör & IRR & Sektör & IRR & Sektör & IRR \\
\hline \multirow{15}{*}{ 牚 } & 1 & 19 & 0.4284 & 19 & 0.4825 & 19 & 0.4059 & 19 & 0.3919 & 19 & 0.4437 & 27 & 0.3371 \\
\hline & 2 & 27 & 0.3002 & 24 & 0.3523 & 24 & 0.2778 & 27 & 0.3209 & 27 & 0.3496 & 19 & 0.3289 \\
\hline & 3 & 24 & 0.2949 & 27 & 0.3366 & 27 & 0.2759 & 22 & 0.2925 & 24 & 0.2976 & 29 & 0.2751 \\
\hline & 4 & 29 & 0.2796 & 25 & 0.3229 & 22 & 0.2655 & 24 & 0.2847 & 29 & 0.2967 & 22 & 0.2746 \\
\hline & 5 & 22 & 0.2714 & 28 & 0.3106 & 25 & 0.2501 & 25 & 0.2760 & 22 & 0.2917 & 24 & 0.2741 \\
\hline & 6 & 28 & 0.2657 & 29 & 0.2989 & 29 & 0.2439 & 29 & 0.2709 & $20 \mathrm{~T} 21$ & 0.2667 & 28 & 0.2423 \\
\hline & 7 & 25 & 0.2612 & 22 & 0.2834 & 28 & 0.2423 & 28 & 0.2682 & 25 & 0.2587 & 26 & 0.2419 \\
\hline & 8 & $35 \mathrm{~T} 39$ & 0.1842 & $35 \mathrm{~T} 39$ & 0.2015 & $20 \mathrm{~T} 21$ & 0.1870 & 26 & 0.2195 & 28 & 0.2567 & 25 & 0.2387 \\
\hline & 9 & $17 \mathrm{~T} 18$ & 0.1806 & $31 \mathrm{~T} 33$ & 0.2000 & $17 \mathrm{~T} 18$ & 0.1793 & $17 \mathrm{~T} 18$ & 0.2031 & 26 & 0.2497 & $20 \mathrm{~T} 21$ & 0.2381 \\
\hline & 10 & $20 \mathrm{~T} 21$ & 0.1803 & $20 \mathrm{~T} 21$ & 0.1948 & $31 \mathrm{~T} 33$ & 0.1671 & $20 \mathrm{~T} 21$ & 0.2014 & $17 \mathrm{~T} 18$ & 0.2084 & $17 \mathrm{~T} 18$ & 0.1989 \\
\hline & 11 & $31 \mathrm{~T} 33$ & 0.1760 & $17 \mathrm{~T} 18$ & 0.1893 & 26 & 0.1640 & $31 \mathrm{~T} 33$ & 0.1928 & $31 \mathrm{~T} 33$ & 0.1982 & $31 \mathrm{~T} 33$ & 0.1818 \\
\hline & 12 & $41 \mathrm{~T} 43$ & 0.1723 & $41 \mathrm{~T} 43$ & 0.1783 & $13 \mathrm{~T} 15$ & 0.1621 & $13 \mathrm{~T} 15$ & 0.1772 & 16 & 0.1662 & 16 & 0.1628 \\
\hline & 13 & 26 & 0.1704 & 26 & 0.1708 & $35 \mathrm{~T} 39$ & 0.1583 & $41 \mathrm{~T} 43$ & 0.1650 & $13 \mathrm{~T} 15$ & 0.1657 & $13 \mathrm{~T} 15$ & 0.1574 \\
\hline & 14 & $13 \mathrm{~T} 15$ & 0.1615 & $13 \mathrm{~T} 15$ & 0.1686 & $41 \mathrm{~T} 43$ & 0.1493 & $35 \mathrm{~T} 39$ & 0.1578 & $35 \mathrm{~T} 39$ & 0.1654 & $35 \mathrm{~T} 39$ & 0.1461 \\
\hline & 15 & 23 & 0.1500 & 23 & 0.1659 & 23 & 0.1485 & 23 & 0.1576 & $41 \mathrm{~T} 43$ & 0.1566 & $41 \mathrm{~T} 43$ & 0.1458 \\
\hline \multirow{15}{*}{$\frac{\tilde{a}}{\frac{\pi}{\vec{n}}}$} & 1 & 26 & 0.4741 & 26 & 0.5112 & 26 & 0.5284 & 26 & 0.5466 & 26 & 0.5272 & 26 & 0.5346 \\
\hline & 2 & 29 & 0.3756 & 27 & 0.3831 & 27 & 0.3901 & 27 & 0.4100 & 27 & 0.4237 & 27 & 0.4483 \\
\hline & 3 & 27 & 0.3742 & 29 & 0.3801 & 29 & 0.3628 & 29 & 0.3861 & 29 & 0.4088 & 29 & 0.4279 \\
\hline & 4 & 28 & 0.2852 & 28 & 0.3028 & 22 & 0.2926 & 22 & 0.3063 & 28 & 0.3237 & 28 & 0.3510 \\
\hline & 5 & $13 \mathrm{~T} 15$ & 0.2799 & 25 & 0.2796 & 28 & 0.2851 & 28 & 0.2932 & 22 & 0.3220 & 22 & 0.3365 \\
\hline & 6 & 22 & 0.2788 & 22 & 0.2796 & 25 & 0.2667 & 25 & 0.2836 & 30 & 0.3095 & 30 & 0.3329 \\
\hline & 7 & 25 & 0.2632 & 30 & 0.2677 & 30 & 0.2512 & 30 & 0.2762 & 25 & 0.3022 & 25 & 0.3304 \\
\hline & 8 & 30 & 0.2565 & $17 \mathrm{~T} 18$ & 0.2612 & $17 \mathrm{~T} 18$ & 0.2511 & $17 \mathrm{~T} 18$ & 0.2659 & $13 \mathrm{~T} 15$ & 0.2753 & $31 \mathrm{~T} 33$ & 0.2959 \\
\hline & 9 & $17 \mathrm{~T} 18$ & 0.2488 & $13 \mathrm{~T} 15$ & 0.2541 & $13 \mathrm{~T} 15$ & 0.2474 & $13 \mathrm{~T} 15$ & 0.2655 & $20 \mathrm{~T} 21$ & 0.2743 & $20 \mathrm{~T} 21$ & 0.2893 \\
\hline & 10 & $31 \mathrm{~T} 33$ & 0.2416 & $31 \mathrm{~T} 33$ & 0.2441 & $20 \mathrm{~T} 21$ & 0.2387 & $31 \mathrm{~T} 33$ & 0.2532 & $31 \mathrm{~T} 33$ & 0.2724 & $13 \mathrm{~T} 15$ & 0.2838 \\
\hline & 11 & $20 \mathrm{~T} 21$ & 0.2341 & $20 \mathrm{~T} 21$ & 0.2410 & $31 \mathrm{~T} 33$ & 0.2349 & $20 \mathrm{~T} 21$ & 0.2516 & $17 \mathrm{~T} 18$ & 0.2665 & $17 \mathrm{~T} 18$ & 0.2833 \\
\hline & 12 & 24 & 0.2026 & 24 & 0.2206 & 24 & 0.2012 & 24 & 0.2121 & 24 & 0.2144 & 24 & 0.2388 \\
\hline & 13 & 16 & 0.1698 & 23 & 0.1833 & 23 & 0.1770 & 23 & 0.1956 & 23 & 0.2091 & 23 & 0.2285 \\
\hline & 14 & 23 & 0.1657 & 16 & 0.1728 & 16 & 0.1631 & 16 & 0.1717 & 16 & 0.1752 & 16 & 0.1901 \\
\hline & 15 & $41 \mathrm{~T} 43$ & 0.1316 & $41 \mathrm{~T} 43$ & 0.1406 & $41 \mathrm{~T} 43$ & 0.1298 & $41 \mathrm{~T} 43$ & 0.1430 & $41 \mathrm{~T} 43$ & 0.1466 & 19 & 0.1747 \\
\hline \multirow{15}{*}{ 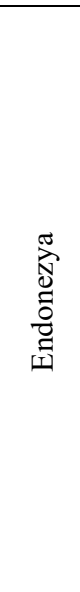 } & 1 & 28 & 0.5039 & 30 & 0.4453 & 30 & 0.4172 & 30 & 0.4128 & 30 & 0.3910 & 30 & 0.3826 \\
\hline & 2 & 30 & 0.4477 & 26 & 0.4234 & 26 & 0.3699 & 26 & 0.3856 & 26 & 0.3632 & 28 & 0.3356 \\
\hline & 3 & 26 & 0.3809 & 28 & 0.3972 & 28 & 0.3200 & 28 & 0.3371 & 28 & 0.3562 & 26 & 0.3175 \\
\hline & 4 & 25 & 0.3181 & 25 & 0.3067 & 22 & 0.2401 & 25 & 0.2681 & 22 & 0.3254 & 25 & 0.2882 \\
\hline & 5 & 19 & 0.3159 & 22 & 0.3057 & 25 & 0.2365 & 22 & 0.2638 & 27 & 0.2958 & 22 & 0.2880 \\
\hline & 6 & 22 & 0.2938 & 19 & 0.3048 & 27 & 0.2283 & 27 & 0.2512 & 25 & 0.2755 & 27 & 0.2495 \\
\hline & 7 & 27 & 0.2695 & 27 & 0.3014 & 19 & 0.2013 & 19 & 0.2048 & $13 \mathrm{~T} 15$ & 0.2365 & $13 \mathrm{~T} 15$ & 0.2239 \\
\hline & 8 & $31 \mathrm{~T} 33$ & 0.2442 & 29 & 0.2358 & 29 & 0.1754 & $13 \mathrm{~T} 15$ & 0.2004 & 19 & 0.2361 & 19 & 0.1914 \\
\hline & 9 & $17 \mathrm{~T} 18$ & 0.2381 & 49T53 & 0.2206 & 90T96 & 0.1671 & 29 & 0.1947 & 29 & 0.2062 & $31 \mathrm{~T} 33$ & 0.1887 \\
\hline & 10 & $90 \mathrm{~T} 96$ & 0.2379 & $31 \mathrm{~T} 33$ & 0.2144 & $13 \mathrm{~T} 15$ & 0.1661 & $31 \mathrm{~T} 33$ & 0.1762 & $31 \mathrm{~T} 33$ & 0.2030 & 29 & 0.1823 \\
\hline & 11 & $13 \mathrm{~T} 15$ & 0.2247 & 90T96 & 0.2089 & $49 \mathrm{~T} 53$ & 0.1629 & 49T53 & 0.1730 & $17 \mathrm{~T} 18$ & 0.1973 & $17 \mathrm{~T} 18$ & 0.1769 \\
\hline & 12 & 29 & 0.2154 & $13 \mathrm{~T} 15$ & 0.2050 & $31 \mathrm{~T} 33$ & 0.1567 & $20 \mathrm{~T} 21$ & 0.1721 & $20 \mathrm{~T} 21$ & 0.1884 & $90 \mathrm{~T} 96$ & 0.1652 \\
\hline & 13 & 24 & 0.2104 & $20 \mathrm{~T} 21$ & 0.1962 & $20 \mathrm{~T} 21$ & 0.1564 & 90T96 & 0.1688 & $90 \mathrm{T96}$ & 0.1843 & $20 \mathrm{~T} 21$ & 0.1591 \\
\hline & 14 & $20 \mathrm{~T} 21$ & 0.2103 & $17 \mathrm{~T} 18$ & 0.1875 & $17 \mathrm{~T} 18$ & 0.1440 & $17 \mathrm{~T} 18$ & 0.1598 & $49 \mathrm{~T} 53$ & 0.1832 & 24 & 0.1514 \\
\hline & 15 & $49 \mathrm{~T} 53$ & 0.2055 & $41 \mathrm{~T} 43$ & 0.1803 & $41 \mathrm{~T} 43$ & 0.1342 & $41 \mathrm{~T} 43$ & 0.1433 & $41 \mathrm{~T} 43$ & 0.1601 & $41 \mathrm{~T} 43$ & 0.1441 \\
\hline
\end{tabular}

Kaynak. OECD Girdi-Çıktı tablolarından yararlanılarak yazar tarafından hesaplanmıştır.

${ }^{5}$ IRR, ithalat gereklilik oranını (import requirements ratio) ifade etmektedir. Sektör kodları ve tanımları Ek Tablo 1'de yer almaktadır. 
Tablo 1 Türkiye, Meksika ve Endonezya ekonomilerinde mal ve hizmet üretiminde ithal ara girdi bağımlılık oranını göstermektedir. Türkiye ekonomisi için elde edilen bulgular değerlendirildiğinde, ithal ara girdi bağımlılığı en yüksek olan sektörün kok kömürü ve rafine edilmiş petrol ürünleri imalatı (19) olduğu ve 2015 yılına gelindiğinde ise ithalat bağımlılı̆g en yüksek olan sektörün elektrikli teçhizat imalatı (27) olduğu görülmektedir. 2015 yılı itibariyle Türkiye ekonomisinde ithal ara mal bağımlılığı en yüksek olan ilk beş sektör sırasıyla elektrikli teçhizat imalatı (27), kok kömürü ve rafine edilmiş petrol ürünleri imalatı (19), motorlu kara taşıtları, treyler (römork) ve yar treyler (yarı römork) imalatı (29), kauçuk ve plastik ürünleri imalatı (22), ana metal sanayi (24) sektörleridir. Meksika ekonomisinde yıllar itibariyle ithal ara girdi bağımlılığı en yüksek olan sektör bilgisayarların, elektronik ve optik ürünlerin imalatı (26) sektörüdür. 2015 yılına gelindiğinde bilgisayarların, elektronik ve optik ürünlerin imalatı (26) sektöründen sonra ithalat bağımlılığı yüksek olan sektörler sırasıyla elektrikli teçhizat imalatı (27), motorlu kara taşıtları, treyler (römork) ve yarı treyler (yarı römork) imalatı (29), başka yerde sınıflandırılmamış makine ve teçhizat imalatı (28), kauçuk ve plastik ürünleri imalatı (22) şeklindedir. Endonezya ekonomisinde ise, genel anlamda ithal ara girdi bağımlılığı en yüksek olan sektör diğer ulaşım araçlarının imalatı (30) sektörüdür. Endonezya ekonomisinde 2015 yılına gelindiğinde ulaşım araçlarının imalatı (30) sektöründen sonra ithal ara girdi bağımlılı̆̆ı en yüksek olan sektörler sırasıyla başka yerde sınıflandırılmamış makine ve teçhizat imalatı (28), bilgisayarların, elektronik ve optik ürünlerin imalatı (26), makine ve teçhizat hariç, fabrikasyon metal ürünleri imalatı (25), kauçuk ve plastik ürünleri imalatı (22) sektörleridir.

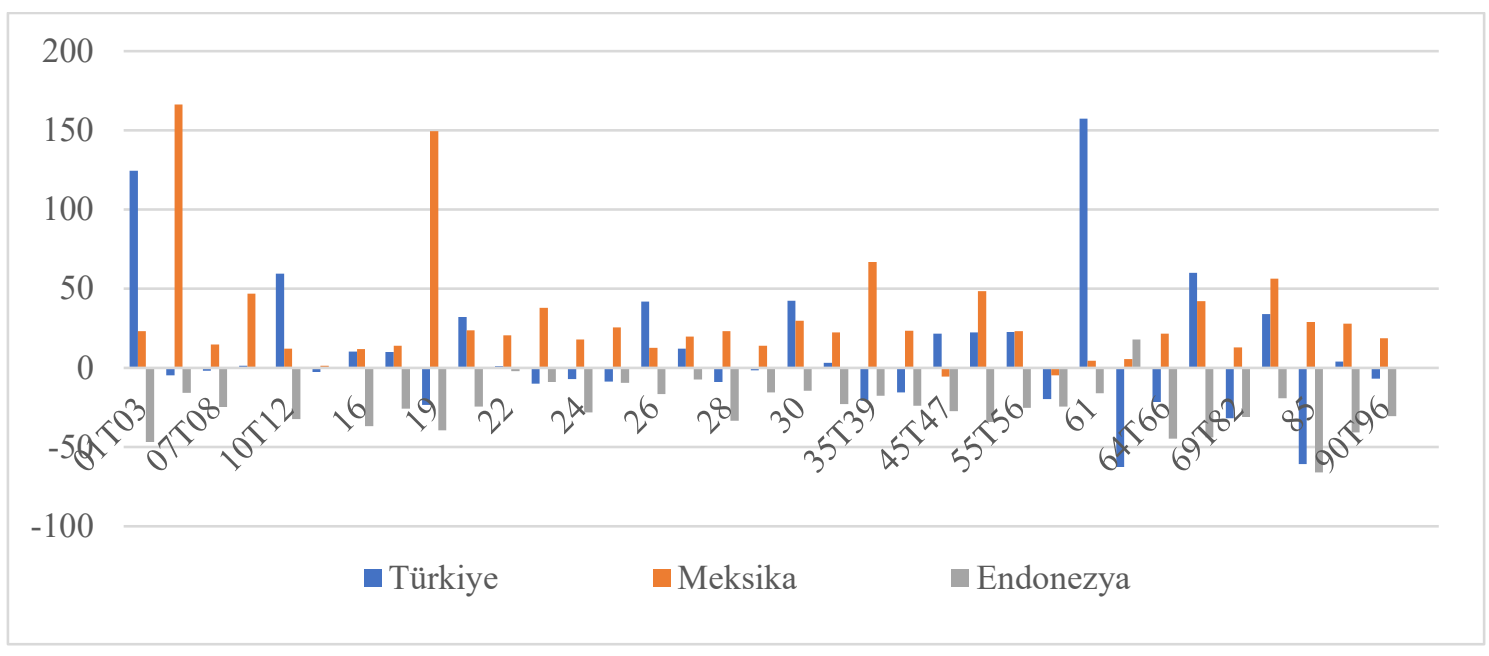


Şekil 1. MINT ülkelerinde 2005-2015 y1llarında ithal ara girdi bağımlığ́ yüzde değişimi. OECD girdi-çıktı tablolarından yararlanılarak yazar tarafından hesaplanmıştır.

Şekil 1 Türkiye, Meksika ve Endonezya ekonomilerinde 2005 yılından 2015 yılına gelindiğinde sektörel üretimin ithalat bağımlılığının yüzde değişimini göstermektedir. Türkiye ekonomisinde ithalat bağımlılı̆̆ı bakımdan en yüksek yüzde artış telekomünikasyon (61) sektöründe gerçekleşmiştir. Bu anlamda telekomünikasyon (61) sektöründe ithalat bağımlılığı \%157 civarında artış göstermiştir. Telekomünikasyon sektöründen sonra ithalat bağımlılığı artış gösteren ikinci en yüksek sektör tarım, ormancılık ve balıkçılık (01T03) sektörüdür. Bu sektörde dönem itibariyle ithalat bağımlılı̆̆1 \%125 artış göstermiştir. Bu bağlamda dönem sonunda ithalat bağımlılığı en fazla artan sektörler gıda ürünleri, içecek ve tütün ürünleri imalatı (10T12) \%60, gayri menkul faaliyetleri (68) \%60, bilgisayarların, elektronik ve optik ürünlerin imalatı (26) \%42, diğer ulaşım araçlarının imalatı (30) \%42 ve kimyasal ve eczacılık ürünleri imalatı (20T21) \%32 şeklindedir. Meksika ekonomisinde ise en yüksek ithalat bağımlılı̆̆ artışı enerji üreten ürünlerin çıkarılması ve madencilik (05T06) sektörüdür. Bu sektörde ithalat bağımlılığı \%166 artış göstermiştir. İthalatın en fazla artığı diğer önemli bir sektör ise kok kömürü ve rafine edilmiş petrol ürünleri imalatı (19) \%149 sektörüdür. Kok kömürü ve rafine edilmiş petrol ürünleri imalatı (19) Meksika ve Türkiye ekonomilerinde farklı bir eğilim göstermiştir. Türkiye ekonomisinde bu sektörün ithalat bağımlılığı \%23 azalırken Meksika ekonomisinde \%149 artmıştır. Endonezya ekonomisinde ise bütün sektörlerde 2015 yılına gelindiğinde ithalat bağımlılığının azaldığına yönelik bulgular elde edilmiştir.

Tablo 2 Türkiye, Meksika ve Endonezya ekonomilerinde nihai talep bileşenlerinin ithalat içeriklerini göstermektedir. Türkiye ekonomisinde ithalat bağımlılığı en yüksek olan iki bileşen yatırım harcamaları ve ihracat bileşenleridir. Nihai ihracatın ithalat içeriği dönem boyunca ortalama \%18 iken yatırım harcamalarının ithalat içeriğgi ortalama \%17'dir. İthalat bağımlılı̆g en düşük olan nihai talep bileşeni ise kamu harcamaları bileşenidir. Türkiye ekonomisinde 2005-2015 yılları arasında toplam nihai talebin ortalama \%13’ü ithalat oluşturmaktadır. Meksika ekonomisinde ithalat bağımlılığı en yüksek olan bileşen nihai ihracat bileşenidir. Dönem başında ihracatın ithalat bağımlılığ1 \%24 iken dönem sonunda bu oran \%32'ye çıkmıştır. Meksika ekonomisinde ihracattan sonra ithalat bağımlılı̆̆ı en yüksek olan ikinci bileşen nihai yatırım harcamalarıdır. Toplam nihai talebin ithalat bağımlılı̆̆ı dönem boyunca ortalama \%15'tir. Endonezya ekonomisinde ise ithalat bağımlılı̆̆ı en yüksek olan nihai talep bileșeni yatırım 
harcamalarıdır. Endonezya ekonomisinde hem ihracatın hem de yatırım harcamalarının ithalata bağımlılığı dönem boyunca düşüş eğiliminde olduğu görülmektedir. Nihai talebin ithalat bağımlılı̆̆ dönem boyunca ortalama \%13'tür. Meksika ve Türkiye ekonomilerinde nihai talebin ithalat bağımlılığı artış gösterirken Endonezya ekonomisinde düşüş göstermiştir.

Tablo 2

MINT Ülkelerinde Nihai Talep Bileşenlerinin İthalat İçerikleri

\begin{tabular}{|c|c|c|c|c|c|c|c|c|c|c|c|c|}
\hline & & 2005 & 2006 & 007 & 008 & 2009 & 2010 & 2011 & 2012 & 201 & 2014 & 20 \\
\hline & $\mathrm{C}$ & 18 & 63 & 58 & 92 & 788 & 46 & 0 & 9.9 & 10. & 10.27 & 9.39 \\
\hline & G & & & 40 & & 74 & & & & & & 6 \\
\hline & I & 17.26 & 7.93 & 7.69 & 18.19 & 15.58 & 17.22 & & & & & 5.22 \\
\hline & Exp & 15.43 & 17.55 & 18.17 & 19.67 & 15.70 & 17.23 & 16 & 20.52 & & 2 & 6.83 \\
\hline & 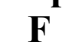 & 11.63 & 12.62 & 12.59 & 13.36 & 11.08 & 12.11 & 13.96 & 14 & 13 & 13.33 & 12.27 \\
\hline \multirow{5}{*}{$\frac{\sqrt{5}}{\frac{\pi}{2}}$} & C & & & & & & & & & & & 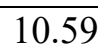 \\
\hline & G & & & & & 6 & & & & & & \\
\hline & I & .12 & 6.39 & 5.42 & 6.07 & 4.80 & 5 & & & & 15.46 & 16.20 \\
\hline & Exp & 24.48 & 24.97 & 24.69 & 25.44 & 26.22 & 27.64 & & 28 & 28.69 & 28.74 & 31.58 \\
\hline & t & 13.53 & 13.89 & 13.93 & 14.24 & 13.62 & 14.88 & 15.07 & 15.85 & 15.45 & 15.46 & 17.18 \\
\hline \multirow{5}{*}{ 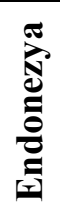 } & C & 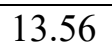 & 12. & 11.9 & 12 & & 10. & & 11 & 11 & 11.45 & 9.66 \\
\hline & G & & & & & & & & & & & \\
\hline & $=$ & .88 & $.0 c$ & 17.13 & & 15.09 & & & & & 17.29 & 15.49 \\
\hline & $\operatorname{Exp}$ & 18.48 & 15.01 & 14.43 & 15.09 & 12.22 & 12.57 & 13.01 & 13. & 14.06 & 14.24 & 13.04 \\
\hline & F & 15.90 & 13.82 & 13.53 & 14.59 & 11.26 & 11.86 & 12.65 & 13.00 & 13.18 & 13.22 & 11.53 \\
\hline
\end{tabular}

Kaynak. OECD Girdi-Çıktı tablolarından yararlanarak yazar tarafından hesaplanmıştır. C: Hane Halkı Tüketimi, G: Kamu harcamaları, I: Yatırımı, Exp: İhracat, F: Toplam Nihai Talep

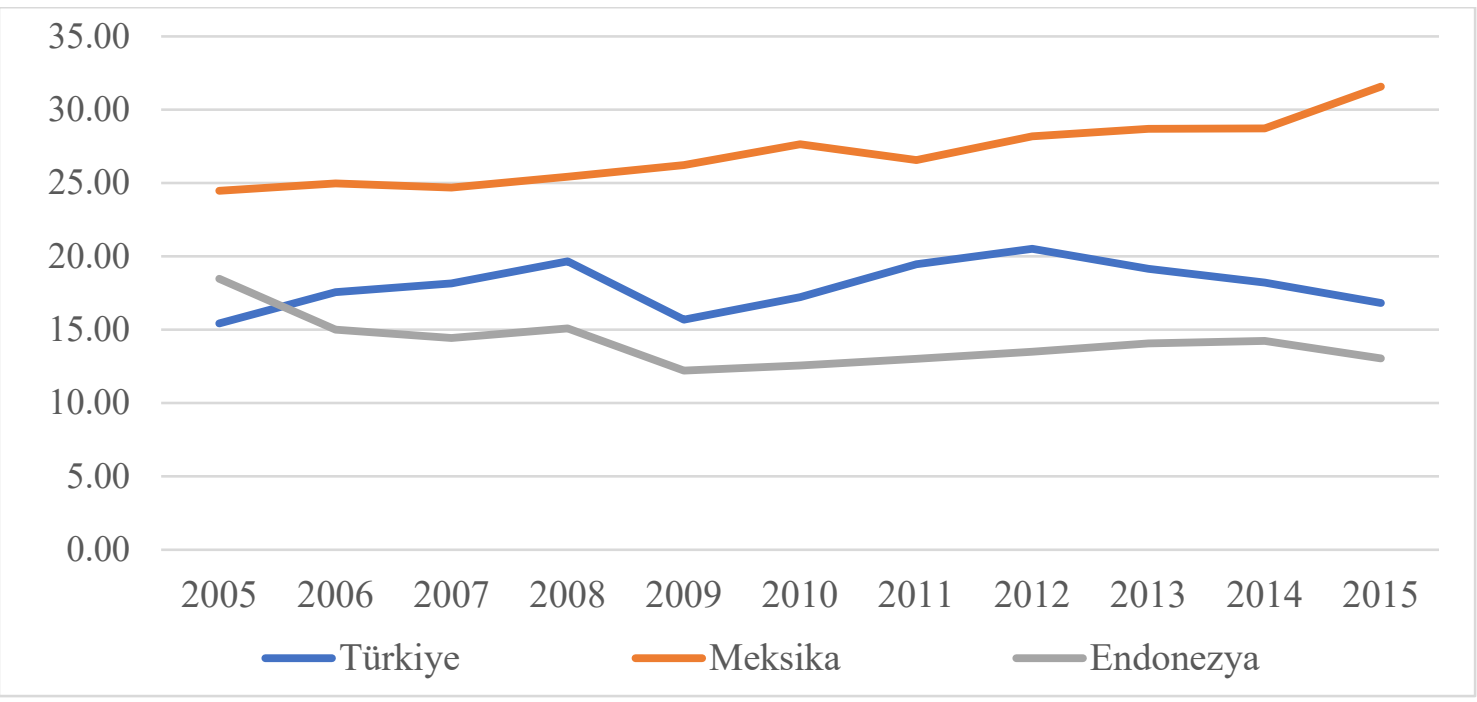

Şekil 2. MINT ülkelerinde dikey uzmanlaşma oranı. OECD girdi-çıktı tablolarından yararlanarak yazar tarafindan hesaplanmıştır. 
Şekil 2, Tablo 6'da yer alan $\boldsymbol{E x p}$ bileşenin dönem boyunca eğilimini göstermektedir. Dikey uzmanlaşma oranın göstergesi olan ihracatın ithalata bağımlılık oranı değerlendirildiğinde Şekil 2'de görüldüğü üzere, dikey uzmanlaşma oran en yüksek olan ülke Meksika'dır. Meksika ekonomisinde dikey uzmanlaşma oranı 2010-2011 dönemi hariç genel olarak artış eğilimi göstermiştir. Meksika'dan sonra dikey uzmanlaşma oranı yüksek olan diğer ülke Türkiye'dir. Şekil 2 incelendiğinde özellikle 2008-2009 küresel finansal kriz döneminde Türkiye'nin dikey uzmanlaşma oranının keskin bir şekilde düştüğü görülmektedir. 2008-2009 küresel finansal krizden sonra tekrar artış eğiliminde olmakla birlikte 2012 yılından sonra istikrarlı bir şekilde düşme eğiliminde olduğu görülmektedir. Bu ülkeler arasında dikey uzmanlaşma oranı en düşük olan ülke Endonezya'dır. Endonezya ekonomisinde dikey uzmanlaşma oranı dönem boyunca sürekli azaldığı görülmektedir. En keskin düşüş ise Türkiye ekonomisinde benzer bir şekilde 20082009 küresel finansal krize denk geldiği görülmektedir.

Tablo 3 Türkiye, Meksika ve Endonezya ekonomilerinde sektörlerin dikey uzmanlaşma oranları yüksek olan ilk 15 alt sektör yer almaktadır. Türkiye ekonomisinde dikey uzmanlaşma oranı en yüksek olan sektör kok kömürü ve rafine edilmiş petrol ürünleri imalat1 (19) alt sektörüdür. Fakat 2015 yılına gelindiğinde dikey uzmanlaşma oranı en yüksek olan sektör elektrikli teçhizat imalatı (27) alt sektörüdür. Genel olarak değerlendirildiğinde Türkiye ekonomisinde dikey uzmanlaşma oranının yüksek olduğu sektörler imalat sanayi alt sektörleri olduğu görülmektedir. Meksika ekonomisinde dikey uzmanlaşmanın en yüksek olduğu sektör bilgisayarların, elektronik ve optik ürünlerin imalatı (26) alt sektörüdür. Türkiye ekonomisine benzer şekilde Meksika ekonomisinde de dikey uzmanlaşma oranın en yüksek olduğu sektörler genel anlamda imalat sanayisi alt sektörleri olduğuna yönelik bulgular elde edilmiştir. Endonezya ekonomisinde ise dikey uzmanlaşmanın en yüksek olduğu sektör diğer ulaşım araçları imalatı (30) alt sektörüdür. Bu sektörden sonra dikey uzmanlaşma oranının en yüksek olduğu sektör başka yerde sınıflandırılmamış makine ve teçhizat imalatı (28) alt sektörüdür. 2015 yılında ilk 15 sektör içerisinde dikey uzmanlaşmanın en düşük olduğu sektör Türkiye'de inşaat (41T43), Meksika'da kok kömürü ve rafine edilmiş petrol ürünleri imalatı (19) ve Endonezya'da taşıma ve depolama (49T53) alt sektörleridir. 
Tablo 3

MINT Ülkelerinde Sektörel Bazda Dikey Uzmanlaşma ${ }^{6}$

\begin{tabular}{|c|c|c|c|c|c|c|c|c|c|c|c|c|c|}
\hline \multirow{2}{*}{ Ülke } & \multirow{2}{*}{ Siralama } & \multicolumn{2}{|c|}{2005} & \multicolumn{2}{|c|}{2008} & \multicolumn{2}{|c|}{2009} & \multicolumn{2}{|c|}{2010} & \multicolumn{2}{|c|}{2014} & \multicolumn{2}{|c|}{2015} \\
\hline & & Sektör & VS & Sektör & VS & Sektör & VS & Sektör & VS & Sektör & VS & Sektör & VS \\
\hline \multirow{15}{*}{ 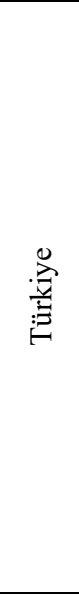 } & 1 & 19 & 43 & 19 & 48 & 19 & 41 & 19 & 39 & 19 & 44 & 27 & 34 \\
\hline & 2 & 27 & 30 & 24 & 35 & 24 & 28 & 27 & 32 & 27 & 35 & 19 & 33 \\
\hline & 3 & 24 & 29 & 27 & 34 & 27 & 28 & 22 & 29 & 24 & 30 & 29 & 28 \\
\hline & 4 & 29 & 28 & 25 & 32 & 22 & 27 & 24 & 28 & 29 & 30 & 22 & 27 \\
\hline & 5 & 22 & 27 & 28 & 31 & 25 & 25 & 25 & 28 & 22 & 29 & 24 & 27 \\
\hline & 6 & 28 & 27 & 29 & 30 & 29 & 24 & 29 & 27 & $20 \mathrm{~T} 21$ & 27 & 28 & 24 \\
\hline & 7 & 25 & 26 & 22 & 28 & 28 & 24 & 28 & 27 & 25 & 26 & 26 & 24 \\
\hline & 8 & 35 T39 & 18 & $35 \mathrm{~T} 39$ & 20 & $20 \mathrm{~T} 21$ & 19 & 26 & 22 & 28 & 26 & 25 & 24 \\
\hline & 9 & $17 \mathrm{~T} 18$ & 18 & $31 \mathrm{~T} 33$ & 20 & $17 \mathrm{~T} 18$ & 18 & $17 \mathrm{~T} 18$ & 20 & 26 & 25 & $20 \mathrm{~T} 21$ & 24 \\
\hline & 10 & $20 \mathrm{~T} 21$ & 18 & $20 \mathrm{~T} 21$ & 19 & $31 \mathrm{~T} 33$ & 17 & $20 \mathrm{~T} 21$ & 20 & $17 \mathrm{~T} 18$ & 21 & $17 \mathrm{~T} 18$ & 20 \\
\hline & 11 & $31 \mathrm{~T} 33$ & 18 & $17 \mathrm{~T} 18$ & 19 & 26 & 16 & $31 \mathrm{~T} 33$ & 19 & $31 \mathrm{~T} 33$ & 20 & $31 \mathrm{~T} 33$ & 18 \\
\hline & 12 & $41 \mathrm{~T} 43$ & 17 & $41 \mathrm{~T} 43$ & 18 & $13 \mathrm{~T} 15$ & 16 & $13 \mathrm{~T} 15$ & 18 & 16 & 17 & 16 & 16 \\
\hline & 13 & 26 & 17 & 26 & 17 & $35 \mathrm{~T} 39$ & 16 & $41 \mathrm{~T} 43$ & 17 & $13 \mathrm{~T} 15$ & 17 & $13 \mathrm{~T} 15$ & 16 \\
\hline & 14 & $13 \mathrm{~T} 15$ & 16 & $13 \mathrm{~T} 15$ & 17 & $41 \mathrm{~T} 43$ & 15 & 35 T39 & 16 & 35 T39 & 17 & 35 T39 & 15 \\
\hline & 15 & 23 & 15 & 23 & 17 & 23 & 15 & 23 & 16 & $41 \mathrm{~T} 43$ & 16 & $41 \mathrm{~T} 43$ & 15 \\
\hline \multirow{15}{*}{ 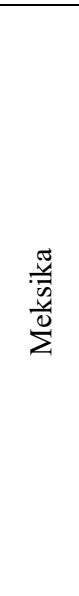 } & 1 & 26 & 47 & 26 & 51 & 26 & 53 & 26 & 55 & 26 & 53 & 26 & 53 \\
\hline & 2 & 29 & 38 & 27 & 38 & 27 & 39 & 27 & 41 & 27 & 42 & 27 & 45 \\
\hline & 3 & 27 & 37 & 29 & 38 & 29 & 36 & 29 & 39 & 29 & 41 & 29 & 43 \\
\hline & 4 & 28 & 29 & 28 & 30 & 22 & 29 & 22 & 31 & 28 & 32 & 28 & 35 \\
\hline & 5 & $13 \mathrm{~T} 15$ & 28 & 25 & 28 & 28 & 29 & 28 & 29 & 22 & 32 & 22 & 34 \\
\hline & 6 & 22 & 28 & 22 & 28 & 25 & 27 & 25 & 28 & 30 & 31 & 30 & 33 \\
\hline & 7 & 25 & 26 & 30 & 27 & 30 & 25 & 30 & 28 & 25 & 30 & 25 & 33 \\
\hline & 8 & 30 & 26 & $17 \mathrm{~T} 18$ & 26 & $17 \mathrm{~T} 18$ & 25 & $17 \mathrm{~T} 18$ & 27 & $13 \mathrm{~T} 15$ & 28 & $31 \mathrm{~T} 33$ & 30 \\
\hline & 9 & $17 \mathrm{~T} 18$ & 25 & $13 \mathrm{~T} 15$ & 25 & $13 \mathrm{~T} 15$ & 25 & $13 \mathrm{~T} 15$ & 27 & $20 \mathrm{~T} 21$ & 27 & $20 \mathrm{~T} 21$ & 29 \\
\hline & 10 & $31 \mathrm{~T} 33$ & 24 & $31 \mathrm{~T} 33$ & 24 & $20 \mathrm{~T} 21$ & 24 & $31 \mathrm{~T} 33$ & 25 & $31 \mathrm{~T} 33$ & 27 & $13 \mathrm{~T} 15$ & 28 \\
\hline & 11 & $20 \mathrm{~T} 21$ & 23 & $20 \mathrm{~T} 21$ & 24 & $31 \mathrm{~T} 33$ & 23 & $20 \mathrm{~T} 21$ & 25 & $17 \mathrm{~T} 18$ & 27 & $17 \mathrm{~T} 18$ & 28 \\
\hline & 12 & 24 & 20 & 24 & 22 & 24 & 20 & 24 & 21 & 24 & 21 & 24 & 24 \\
\hline & 13 & 16 & 17 & 23 & 18 & 23 & 18 & 23 & 20 & 23 & 21 & 23 & 23 \\
\hline & 14 & 23 & 17 & 16 & 17 & 16 & 16 & 16 & 17 & 16 & 18 & 16 & 19 \\
\hline & 15 & $58 \mathrm{~T} 60$ & 13 & $41 \mathrm{~T} 43$ & 14 & $41 \mathrm{~T} 43$ & 13 & $41 \mathrm{~T} 43$ & 14 & $41 \mathrm{~T} 43$ & 15 & 19 & 17 \\
\hline \multirow{15}{*}{ 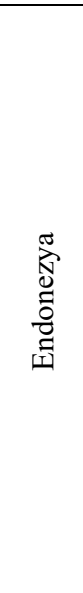 } & 1 & 28 & 50 & 30 & 45 & 30 & 42 & 30 & 41 & 30 & 39 & 30 & 38 \\
\hline & 2 & 30 & 45 & 26 & 42 & 26 & 37 & 26 & 39 & 26 & 36 & 28 & 34 \\
\hline & 3 & 26 & 38 & 28 & 40 & 28 & 32 & 28 & 34 & 28 & 36 & 26 & 32 \\
\hline & 4 & 25 & 32 & 25 & 31 & 22 & 24 & 25 & 27 & 22 & 33 & 25 & 29 \\
\hline & 5 & 19 & 32 & 22 & 31 & 25 & 24 & 22 & 26 & 27 & 30 & 22 & 29 \\
\hline & 6 & 22 & 29 & 19 & 30 & 27 & 23 & 27 & 25 & 25 & 28 & 27 & 25 \\
\hline & 7 & 27 & 27 & 27 & 30 & 19 & 20 & 19 & 20 & $13 \mathrm{~T} 15$ & 24 & $13 \mathrm{~T} 15$ & 22 \\
\hline & 8 & $31 \mathrm{~T} 33$ & 24 & 29 & 24 & 29 & 18 & $13 \mathrm{~T} 15$ & 20 & 19 & 24 & 19 & 19 \\
\hline & 9 & $17 \mathrm{~T} 18$ & 24 & 49T53 & 22 & 90T96 & 17 & 29 & 19 & 29 & 21 & $31 \mathrm{~T} 33$ & 19 \\
\hline & 10 & 90T96 & 24 & $31 \mathrm{~T} 33$ & 21 & $13 \mathrm{~T} 15$ & 17 & $31 \mathrm{~T} 33$ & 18 & $31 \mathrm{~T} 33$ & 20 & 29 & 18 \\
\hline & 11 & $13 \mathrm{~T} 15$ & 22 & $90 \mathrm{~T} 96$ & 21 & 49T53 & 16 & $49 \mathrm{~T} 53$ & 17 & $17 \mathrm{~T} 18$ & 20 & $17 \mathrm{~T} 18$ & 18 \\
\hline & 12 & 29 & 22 & $13 \mathrm{~T} 15$ & 20 & $31 \mathrm{~T} 33$ & 16 & $20 \mathrm{~T} 21$ & 17 & $20 \mathrm{~T} 21$ & 19 & $90 \mathrm{~T} 96$ & 17 \\
\hline & 13 & 24 & 21 & $20 \mathrm{~T} 21$ & 20 & $20 \mathrm{~T} 21$ & 16 & 90T96 & 17 & $90 \mathrm{~T} 96$ & 18 & $20 \mathrm{~T} 21$ & 16 \\
\hline & 14 & $20 \mathrm{~T} 21$ & 21 & $17 \mathrm{~T} 18$ & 19 & $17 \mathrm{~T} 18$ & 14 & $17 \mathrm{~T} 18$ & 16 & $49 \mathrm{~T} 53$ & 18 & 24 & 15 \\
\hline & 15 & 49T53 & 21 & $58 \mathrm{~T} 60$ & 15 & 24 & 13 & 24 & 14 & $58 \mathrm{~T} 60$ & 15 & $49 \mathrm{~T} 53$ & 14 \\
\hline
\end{tabular}

Kaynak. OECD Girdi-Çıktı tablolarından yararlanarak yazar tarafından hesaplanmıştır.

${ }^{6}$ VS, dikey uzmanlaşmayı (vertical specialisation) ifade etmektedir. Aynı zamanda OECD tarafından yapılan hesaplamada, bu çalışmada elde edilen sonuçlar ile aynı sonuçlar elde edilmiştir.

Bknz: https://stats.oecd.org/Index.aspx?DataSetCode=IOTSI4_2018. 


\section{Sonuç}

Girdi-çıktı modelleri, ekonomide mal ve hizmet üretim faaliyeti gerçekleştiren sektörlerin karşılıklı bağınlaşma yapısını, sektörler tarafından üretilen nihai mal ve hizmetlere olan talebin katma değer yapısını, sektörlerin üretiminde ithal ara girdi bağımlılı̆̆1, nihai talebin ithalat bağımlılık yapısını ve ayrıca sektörlerin dikey uzmanlaşma yapısını net bir şekilde analiz edebilme imkanı sağladığı için önemli bir yöntemdir. Literatürde yer alan çalışmalar, büyüme, istihdam, verimlilik ve uluslararası ticaretin ekonomik büyümeye etkisi gibi makro ekonomik değişkenleri analiz edebilmek için genel olarak ekonometrik gibi ampirik yöntemlere başvurmaktadırlar. Ancak bu çalışmada, pek az araştırmacı tarafından uygulanan girdi-çıktı modelleri uygulanmıştır. Bu nedenle literatüre önemli bir katkı sağlayacaktır. Ayrıca OECD veri tabanında en güncel girdi-çıktı tabloları 2018 yılında derlenen tablolarıdır. Bu anlamıyla çalışma, literatürde yer alan diğer girdi-çıktı analizleri ile farklılaşmaktadır. Küreselleşen dünyada, özellikle parçalı üretimin artması ile birlikte uluslararası ticarete önemli bir role sahip olmaları nedeniyle MINT ülkelerine yönelik bu çalışmanın yapılması ihtiyacı duyulmuştur.

Uluslararası ticaret bağlamında düşünüldüğünde, MINT ülkeleri de küresel anlamda önemli ticari ilişkileri olmakla birlikte aynı zamanda bu ülkeler bulundukları coğrafi bölgelerde de önemli iktisadi rollere sahiptirler. Bu bağlamda MINT ülkelerinde ara girdi ve nihai talebin ithalat bağımlılığı incelendiği bu çalışmada, MINT ülkelerinde özellikle ithal ara girdi bağımlılığının yüksek olduğu görülmüştür. Bu ülkelerde ithal ara girdi bağımlılığı yüksek olan sektörler imalat sanayi alt sektörleri olduğuna yönelik bulgular elde edilmiştir. $\mathrm{Bu}$ anlamda analize dahil edilen üç ülkede ithalat bağımlılı̆̆ın yüksek olduğu sektörler kok kömürü ve rafine edilmiş petrol ürünleri (19), kauçuk ve plastik ürünleri (22), temel metaller imalatı (24), makine ve teçhizat hariç fabrikasyon metal ürünleri imalatı (25), bilgisayarların, elektronik ve optik ürünleri imalatı (26), elektrikli teçhizat imalatı (27), başka yerde sınıflandırılmamış makine ve teçhizat imalatı (28), motorlu kara taşıtı, römork ve yarı römork imalatı (29), diğer ulaşım araçları imalatı (30) şeklindedir.

Nihai talebin açısından değerlendirildiğinde ise, toplam nihai talebin ithalat bağımlılı̆̆ Türkiye'de ortalama \%13, Meksika'da ortalama \%15, Endonezya'da ise ortalama \%13 olarak hesaplanmıştır. Meksika ekonomisinde ithalat bağımlılı̆̆ın en yüksek olduğu nihai talep 
bileşeni ise ihracattır. İhracatın ithalat bağımlılığı ortalama \%27'dir. Türkiye ve Endonezya ekonomilerinde ise nihai yatırım ve ihracat talebinin ithalat bağımlılığının birbirlerine yakın olduğu gözlenmiştir. Genel olarak bu ülkelerde yurtiçi toplam nihai talebin ithalat bağımlılığının daha yüksek olduğuna yönelik bulgular elde edilmiştir. Sektörel anlamda ihracatın ithalat bağımlılığı değerlendirildiğinde ise yine bu ülkelerde özellikle imalat sanayi alt sektörlerinde ihracatın ithalat bağımlılı̆̆ının yüksek olduğu görülmüştür. Bu ülkelerde imalat sanayi alt sektörlerinde ihracatın ithalat bağımlılı̆̆ ortalama \%30-55 arasında değişkenlik göstermektedir. 


\section{Kaynakça}

Ahmad, T., Daryanto, A., Oktaviani, R. \& Priyarsono, D. S. (2018). Global value chain of Indonesian pulp and paper industry. Jurnal Manajemen \& Agribisnis, 15(2), 118-128. doi:http://dx.doi.org/10.17358/jma.15.2.118

Akpan, U. S., Isihak, S. R. \& Asongu, S. A. (2014). Determinants of foreign direct investment in Fast-Growing Economies: A Study of BRIC and MINT. AGDI Working Paper(WP/14/002). African Govarnance and Development Institute. doi:http://dx.doi.org/10.2139/ssrn.2493410

Amar, A., Landau, M. T. \& Wikierman, A. (2016). Descomposicion alternativa de los componentes de la demanda agregada. Estudios Y Perspectivas(47), 1-29.

Aydoğuş, O. (2015). Girdi-çıktı modellerine giriş. Ankara: Efil Yayınevi.

Banacloche, S. \& Cadarso, M. Á. (2020). Implications of measuring value added in exports with a regional input-output table: a case of study in South America. Structural Change and Economic Dynamics, 52, 130-140. doi:https://doi.org/10.1016/j.strueco.2019.08.003

Banga, R. (2014). Linking into global value chains is not sufficient: Do you export domestic value added contents? Journal of Economic Integration, 29(2), 267-297. doi:https://doi.org/10.11130/jei.2014.29.2.267

Bravo, A. C. \& Alvarez, T. M. (2012). The import content of the industrial sectors in Spain. Economic Bulletien, 81, 81-92.

Casadella, V. (2018). Innovation sysyems in emerging economies (Cilt 8). London: Wiley.

Chen, H.-Y. \& Chang, Y.-M. (2006). Trade verticality and structural change in industries: the cases of Taiwan and South Korea. Open Economies Review, 17, 321-340. doi:10.1007/s11079006-9052-y

Constantinescu, C., Mattoo, A. \& Ruta, M. (2019). Does vertical specialisation increase productivity? The World Economy, 42, 2385-2402. doi:10.1111/twec.12801

Cordoso, F., Esteves, P. S. \& Rua, A. (2013). The import content of global demand in Portugal. Economic Bulletin, 19(3), 107-121.

Cruz, J. D., Koopman, R. B. Wang, Z., \& Wei, S.-J. (2013). Foreign and domestic content in Mexico's manufacturing. A. Mattoo, Z. Wang, \& S.-J. Wei içinde, Trade in value added: developing new measures of cross-border trade (s. 135-160). Washington: The World Bank.

Dağıstan, N. (2019). Türkiye'nin dış ticaretindeki dikey uzmanlaşmanın girdi-çıktı modeli ile analizi. Fiscaoeconomia, 3(2), 1-20. doi:10.25295/fsecon.2019.02.001 
Duan, Y., Dietzenbacher, E., Jiang, X., Chen, X. \& Yang, C. (2018). Why has China's vertical specialization declined? Economic Systems Research, 30(2), 178-200. doi:https://doi.org/10.1080/09535314.2018.1431610

Duman, A. \& Özgüzer, G. E. (2013). An input-output analysis of rising imports in Turkey. Ekonomik Yaklaşım, 23(84), 39-54. doi:10.5455/ey.34105

Durotoye, A. (2014). The MINT countries as emerging economic power bloc: prospect and challenges. Developing Country Studies, 4(15), 99-106.

Fahimi, A., Olasehinde-Williams, G. \& Akadiri, S. S. (2020). Examining the causal relationship between globalization and energy consumption in MINT countries: evidence from bootstrap panel granger causality. International Journal of Finance and Economics, 1-11. doi:https://doi.org/10.1002/ijfe.1884

Foster-McGregor, N. \& Stehrer, R. (2013). Value added content of trade: a comprehensive $\begin{array}{llll}\text { approach. } \quad \text { Economics } & \text { Letters, }\end{array}$ doi:http://dx.doi.org/10.1016/j.econlet.2013.05.003

Gandoy, R. (2017). La dependencia importadora de la economia Espanola. Estudios De Economia Aplicada, 35(1), 111-132. doi:10.25115/eea.v35i1.2440

Gündoğdu, C. \& Saracoğlu, D. Ş. (2016). Participation of Turkey in global value chains: an analysis based on World Input Output Databese. ERC Working Papers in Economisc 16/10. Economic Research center. Alınan yer http://erc.metu.edu.tr/en/system/files/menu/series16/1610.pdf.

Haider, A. (2018). The multiplier effects of manufacturing consupmtion. Department of Policy, Research and Statistics Working Paper 10/2018. Vienna: United Nations Industrial development Organization (UNIDO).

He, D. \& Zhang, W. (2010). How dependent is the chinese economy on exports and in what sense has its growth been export-led? Journal of Asian Economics , 21, 87-104. doi:10.1016/j.asieco.2009.04.005

Hummels, D., Ishii, J. \& Yi, K.-M. (2001). The nature and growth of vertical specialization in world trade. Journal of International Economics, 54, 75-96. doi:10.1016/S00221996(00)00093-3

Jangam, B. P. \& Rath, B. N. (2021). Do global value chains enhance or slog economic growth? Applied Economics, 1-19. doi:10.1080/00036846.2021.1897076

Johnson, R. C. \& Noguera, G. (2012). Accounting for intermediates: production sharing and trade in value added. $86,224-236$. doi:10.1016/j.jinteco.2011.10.003

Lenee, T. L. \& Oki, J. (2017). Capital market development and economic growth: evidence from the MINT countries. Journal of Economics and Sustainable Development, 8(2), 68-107. 
Leontief, W. (1986). Input-output economics (2 b.). Oxford: Oxford University Press.

Lopes, J. C. \& Santos, A. (2015). Vertical specialization, global value chains and the changing geography of trade: The Protuguese rubber and plastic industry case. Working Paper. Portugal: Lisbon School of Economics \& Management. Alınan yer https://www.repository.utl.pt/bitstream/10400.5/9251/1/wp122015DEUECE.pdf

Lopez, R. A. \& Yadav, N. (2010). Imports of intermediate inputs and spillover effects: Evidence from Chilean plants. Journal of Development Studies, 46(8), 1385-1403. doi: $10.1080 / 00220380903428423$

Mattioli, E. \& Lamonica, G. R. (2015). The evolution of the vertical specialization in the world economy (1995-2011). Rivista Italiana di Economia Demografia e Statistica, 69(3), 5-26.

Mikulic, D. \& Lovrincevic, Z. (2018). The import content of Croatian economic sectors and final demand. Economic Research, 31(1), 2003-2023. doi: 10.1080/1331677X.2018.1480967

Miller, R. E. \& Blair, P. D. (2009). Input-output analysis foundation and extensions (2 b.). United Kingdom: Cambridge University Press.

Miroudot, M. \& Ye, M. (2018). A Simple and accurate method to calculate domestic and foreign value-added in gross exports. MPRA Paper No: 89907. Germany: Munich Personal RePEc Archive . Alınan yer https://mpra.ub.uni-muenchen.de/89907/

Pahl, S. \& Timmer, M. P. (2019). Patterns of vertical specialisation in trade: Long-run evidence for 91 countries. Review of World Economics, 155, 459-486. doi:10.1007/s10290-01900352-3

Pei, J., Dietzenbacher, E., Oosterhaven, J. \& Yang, C. (2011). Accounting for China's import growth: A structural decomposition for 1997-2005. Environment and Planning, 43, 29712991. doi:10.1068/a43396

Powers, W. M. (2012). The value of value added: Measuring global engagement with gross and value-added trade. Office of Economics working Paper No. 2012-11A. Washington: U.S. International Trade Commission. Alinan yer https://www.usitc.gov/publications/332/EC201211A.pdf

Prete, D. D., Giovannetti, G. \& Marvasi, E. (2018). Global value chains: new evidence for North Africa. International Economics, 153, 42-54. doi: 10.1016/j.inteco.2017.03.002

Pula, G. \& Peltonen, T. A. (2011). Has emerging asia decoupled? An analysis of production and trade linkages using the asian international input-output table. Y.-W. Cheung, V. Kakkar, \& G. Ma içinde, The Evolving Role of Asia in Global Finance (s. 255-286). Bingley: Emerald Group Publishing Limited. doi:10.1108/S1574-8715(2011)0000009016

Raa, T. T. (2005). The economics of input-output analysis. Cambridge University Press.

Reis, H. \& Rau, A. (2009). An input-output analysis: Linkages versus leakages. International Economic Journal, 23(4), 527-544. doi:10.1080/10168730903372323 
Rohman, I. K. (2013). The globalization and stagnation of the ICT sectors in European countries: An input-output analysis. Telecommunications Policy, 37, 387-399. doi:10.1016/j.telpol.2012.05.001

Scherer, L., Koning, A. D. \& Tukker, A. (2019). BRIC and MINT countries' environmental impacts rising despite alleviative consumption patterns. Science of the Total Environment, 665, 5260. doi:10.1016/j.scitotenv.2019.02.103

Stehrer, R. \& Stöllinger , R. (2013). Positioning Austria in the global economy: Value added trade, international production sharing and global linkages. FIW-Research Reports, No.2013/1402. Vienna: FIW-Research Centre International Economics. doi:http://hdl.handle.net/10419/121230

Thirlwall, A. P. (1986). Growth and development with special reference to developing economies. London: Macmillan Education Ltd. doi: 10.1007/978-1-349-06713-8

Timmer, M. P. (2015). An illustrated user guide to the World Input-Output Database: The case of global automotive production. Review of International Economics, 23(3), 575-605. doi: $10.1111 /$ roie. 12178

Timmer, M. P., Miroudut, S. \& Vries, G. J. (2019). Funtional specialisation in trade. Journal of Economic Geography, 19, 1-30. doi:10.1093/jeg/lby056

Veeramani, C. (2019). Fragmentation trade and vertical specialisation: How does South Asia compare with China. Journal of Asian Economic Integration, 1(1), 97-128. doi: $10.1177 / 2631684618821550$

Veeramani, C. \& Dhir, G. (2017). Domestic value added content of India's exports: estimates for 112 Sectors, 1999-2000 to 2012-13. Workin Paper(WP-2017-008). Mumbai: Indira Gandhi Institute of Development Research. Alınan yer http://www.igidr.ac.in/pdf/publication/WP2017-008.pdf

Wang, Z. \& Powers, W. (2009). Value chains in east asian production networks: an international input-output model based analysis. Office of Economics Working Paper No. 2009-10-C. Washington: U.S. International Trade Commission. Alınan yer http://citeseerx.ist.psu.edu/viewdoc/download?doi=10.1.1.539.9669\&rep=rep1\&type=pdf 


\section{Ek Tablo 1}

\section{Sektör Kodları ve Sektör Tanımları}

\begin{tabular}{|c|c|}
\hline $\begin{array}{l}\text { Sektör } \\
\text { Kodları }\end{array}$ & Sektör Tanımı \\
\hline $01 \mathrm{~T} 03$ & Tarım, ormancılık ve balıkçılık \\
\hline $05 \mathrm{~T} 06$ & Kömür, linyit, ham petrol ve doğalgaz çıkarımı \\
\hline $07 \mathrm{~T} 08$ & Metal cevheri, diğer madencilik ve taş ocakçıllğ 1 \\
\hline 09 & Madenciliği destekleyici hizmet faaliyetleri \\
\hline $10 \mathrm{~T} 12$ & Gıda ürünleri, içeçek ve tütün ürünlerin imalatı \\
\hline $13 \mathrm{~T} 15$ & Tekstil ürünleri, giyim eșyalarının, deri ve ilgili ürünlerin imalatı \\
\hline 16 & Ahşap, ağaç ve mantar ürünlerin imalatı (mobilya hariç) \\
\hline $17 \mathrm{~T} 18$ & Kağıt ve bask1 ürünleri imalatı \\
\hline 19 & Kok kömürü ve rafine edilmiş petrol ürünlerin imalat1 \\
\hline $20 \mathrm{~T} 21$ & Kimyasal ve eczacıl1k ürünlerin imalatı \\
\hline 22 & Kauçuk ve plastik ürünlerin imalatı \\
\hline 23 & Diğer metalik olmayan mineral ürünlerin imalatı \\
\hline 24 & Ana metal sanayii \\
\hline 25 & Makine ve teçhizat hariç, fabrikasyon metal ürünlerin imalatı \\
\hline 26 & Bilgisayarların, elektronik ve optik ürünlerin imalatı \\
\hline 27 & Elektrikli teçhizat imalatı \\
\hline 28 & Başka yerde sınıflandırılmamış makine ve teçhizat imalatı \\
\hline 29 & Motorlu kara taşıtı, treyler (römork) ve yarı treyler (yarı römork) imalatı \\
\hline 30 & Diğer ulaşım araçlarının imalatı \\
\hline $31 \mathrm{T33}$ & Diğer imalat; makine ve teçhizatın onarımı ve montaj1 \\
\hline $35 \mathrm{~T} 39$ & Elektrik, gaz, su temini, kanalizasyon, atık ve iyileştirme hizmetleri \\
\hline $41 \mathrm{~T} 43$ & İnşaat \\
\hline $45 \mathrm{~T} 47$ & Toptan ve perakende ticaret; motorlu taşıtların onarımı \\
\hline $49 \mathrm{~T} 53$ & Ulaştırma ve depolama faaliyetleri \\
\hline $55 \mathrm{T56}$ & Konaklama ve yemek hizmetleri \\
\hline $58 \mathrm{~T} 60$ & Yayıncılık, görsel-işitsel ve yayıncılık faaliyetleri \\
\hline 61 & Telekomünikasyon \\
\hline $62 \mathrm{~T} 63$ & Bilgi teknolojileri ve diğer bilgi hizmet faaliyetleri \\
\hline 64T66 & Finans ve sigorta faaliyetleri \\
\hline 68 & Gayrimenkul faaliyetleri \\
\hline 69T82 & Diğer iş sektörü hizmetleri \\
\hline 84 & Kamu yönetimi ve savunma; zorunlu sosyal güvenlik \\
\hline 85 & Eğitim \\
\hline $86 \mathrm{~T} 88$ & İnsan sağlığ1 ve sosyal hizmet faaliyetleri \\
\hline 90T96 & Sanat, eğlence, rekreasyon ve diğer hizmet faaliyetleri \\
\hline 97Т98 & $\begin{array}{l}\text { Hanehalklarının işverenler olarak faaliyetleri; hanehalkları tarafından kendi } \\
\text { kullanımlarına yönelik olarak ayrım yapılmamış mal ve üretim faaliyetleri }\end{array}$ \\
\hline
\end{tabular}

Kaynak: https://stats.oecd.org/Index.aspx?DataSetCode=IOTSI4_2018. 